DOI: $10.1002 /$ ((please add manuscript number))

Article type: Full Paper

\title{
Thieno[3,4-c]pyrrole-4,6-dione-based Polymer Acceptors for High Open-Circuit Voltage All-Polymer Solar Cells
}

Shengjian Liu, ${ }^{\dagger, \&}$ Xin Song, ${ }^{\dagger, \&}$ Simil Thomas, ${ }^{\dagger}$ Zhipeng Kan, ${ }^{\dagger}$ Federico Cruciani,$^{\dagger}$ Frédéric Laquai,,$^{\dagger}$ Jean-Luc Bredas, ${ }^{\dagger}$ and Pierre M. Beaujuge ${ }^{*, \dot{\dagger}}$

Dr. S. Liu, X. Song, Dr. S. Thomas, Dr. Z. Kan, F. Cruciani, Prof. F. Laquai, Prof. J.-L. Bredas, and Prof. P. M. Beaujuge Physical Sciences and Engineering Division KAUST Solar Center (KSC) King Abdullah University of Science and Technology (KAUST) Thuwal 23955-6900, Saudi Arabia

E-mail: pierre.beaujuge@kaust.edu.sa

Keywords: all-polymer solar cells, polymer acceptors, thieno[3,4-c]pyrrole-4,6-dione, 3,4difluorothiophene, organic photovoltaics

\section{Abstract}

While polymer acceptors are promising fullerene alternatives in the fabrication of efficient bulk heterojunction (BHJ) solar cells, the range of efficient material systems relevant to the "allpolymer" BHJ concept remains narrow, and currently limits the perspectives to meet the $10 \%$ efficiency threshold in all-polymer solar cells. This report examines two polymer acceptor analogues composed of thieno[3,4-c]pyrrole-4,6-dione (TPD) and 3,4-difluorothiophene ([2F]T) motifs, and their BHJ solar cell performance pattern with a low-bandgap polymer donor commonly used with fullerenes (PBDT-TS1; taken as a model system). In this material set, the 


\section{WILEY-VCH}

introduction of a third electron-deficient motif - namely 2,1,3-benzothiadiazole (BT) - is shown to (i) significantly narrow the optical gap ( $\left.E_{\mathrm{opt}}\right)$ of the corresponding polymer (by $c a .0 .2 \mathrm{eV}$ ) and (ii) improve the electron mobility of the polymer by over two orders of magnitude in BHJ solar cells. In turn, the narrow-gap P2TPDBT[2F]T analogue $\left(E_{\mathrm{opt}}=1.7 \mathrm{eV}\right)$ used as fullerene alternative yields high open-circuit voltages $\left(V_{\mathrm{OC}}\right)$ of $c a .1 .0 \mathrm{~V}$, notable short-circuit current values $\left(J_{\mathrm{SC}}\right)$ of $c a .11 .0 \mathrm{~mA} \mathrm{~cm}{ }^{-2}$, and power conversion efficiencies (PCEs) nearing $5 \%$ in allpolymer BHJ solar cells. P2TPDBT[2F]T paves the way to a new, promising class of polymer acceptor candidates.

\section{Introduction}

Bulk heterojunction (BHJ) solar cells consisting of a $\pi$-conjugated polymer donor blended with a polymer acceptor used as fullerene alternative (e.g. phenyl-C61-butyric acid methyl ester, $\mathrm{PC}_{61} \mathrm{BM}$; or its $\mathrm{C}_{71}$ analogue, $\mathrm{PC}_{71} \mathrm{BM}$ ) have met with limited efficiencies in the early years of developments. ${ }^{[1-2]}$ In BHJs composed of two $\pi$-conjugated polymers, concurrently achieving (i) adequate energy band alignements and charge transfer between donor and acceptor components, (ii) balanced carrier mobilities, and (iii) the appropriate donor/acceptor interpenetrating network morphology, requires sequential and systematic material and device optimizations. In turn, while BHJ solar cells composed of polymer donors and fullerene acceptors can achieve power conversion efficiencies (PCEs) $>11 \%,{ }^{[3-4]}$ only a few polymer acceptors have been shown to yield BHJ device PCEs $>5 \%$ thus far. ${ }^{[5-10]}$ 


\section{WILEY-VCH}

The lack of morphological stability and mechanical conformability of fullerene-based BHJ solar cells justifies the development of nonfullerene replacements, including polymer acceptors. ${ }^{[9-10]}$ Nonfullerene acceptors are commonly expected to be more synthetically accessible and cost-competitive than their PCBM counterparts that are known to involve tedious syntheses and extensive purifications. ${ }^{[5-11]}$ The perspective of leveraging specific optical and electronic properties (i.e. electron affinities (EAs), ionization potentials (IPs), spectral absorption, etc.) by design is another key advantage when considering polymer acceptors as alternatives to PCBM; noting that fullerene derivatizations have either modest effects on their electronics and spectral absorption, ${ }^{[12-14]}$ or commonly yield reduced material efficiencies in BHJ devices with polymer donors. ${ }^{[15-17]}$ In principle, polymer acceptors should have an absorption spectrum complementary to that of the donor counterpart, and the appropriate electron transport pattern to avoid space-charge build-ups induced in BHJ active layers with a significant carrier mobility imbalance. ${ }^{[5-10]}$

At present, most efficient polymer acceptors involve perylenediimide (PDI ${ }^{[18-22]}$ or naphthalenediimide (NDI) electron-deficient motifs, ${ }^{[9,23-29]}$ and several studies have shown that analogues designed with PDI/NDI motifs can achieve PCEs of 5-8\% in BHJ solar cells with selected polymer donors. ${ }^{[9-10,18-29]} \mathrm{B} \leftarrow \mathrm{N}$ bridged bipyridine (BNBP)-based polymer acceptors represent another emerging class of promising fullerene alternatives that has recently been shown to reach PCEs of $c a .6 \%{ }^{[30]}$ Several other acceptor motifs are being examined, such as 


\section{WILEY-VCH}

diketopyrrolopyrrole, ${ }^{[31]}$ benzothiadiazole, ${ }^{[32-33]}$ isoindigo, ${ }^{[34]}$ and various nitrile(CN)-derived motifs $;{ }^{[1,35]}$ with reported PCEs in range of $1-4 \%$. However, to date, polymer acceptor developments remain synthetically challenging, and the manifold of electron-deficient motifs and polymer acceptor candidates that can rival fullerenes for efficient BHJ solar cells with polymer donors remains modest. ${ }^{[18-35]}$ Further examinations of the "all-polymer" BHJ concept require that the class of polymer acceptors that can potentially outperform fullerenes be widened and, at this stage, forging a better understanding of the design parameters that directly impact polymer acceptor performance in BHJ solar cells is a key step towards high-performing material systems and BHJ devices.

Thieno[3.4-c]pyrrole-4,6-dione (TPD) motifs have proven particularly useful in the design of polymer donors with optical gaps $\left(E_{\mathrm{opt}}\right)$ narrower than that of the benchmark polymer donor

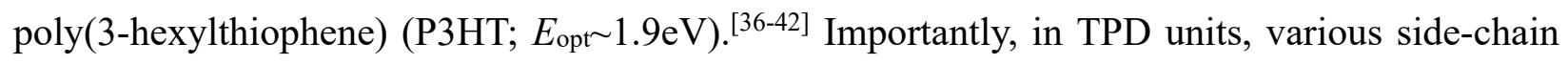
substituents can be appended at the imide site, providing leverage for solubility when the electron-deficient motif is polymerized with other co-monomers. ${ }^{[36,43-44]}$ It is worth noting that many of the most useful electron-deficient units used in the design of narrow-gap polymer donors do not usually possess anchoring sites for the substitution of side-chain substituents. ${ }^{[8]}$ Turning to polymer acceptors, alternating sequences of one or several TPD units ${ }^{[45-47]}$ with other electron-deficient motifs may represent an alternative design approach to achieving electrontransport materials that can be adequately soluble, while possessing sufficiently high ionization 


\section{WILEY-VCH}

potential (IP) and electron affinity (EA) values (corresponding to low-lying HOMO and LUMO energy levels) to be used as nonfullerene acceptors in BHJ solar cells. In recent work, we showed that 3,4-difluorothiophene $([2 \mathrm{~F}] \mathrm{T})$ motifs can also be used to concurrently increase the IP and EA in polymers for BHJ solar cells with PCBM acceptors. ${ }^{[48]}$ In turn, polymers combining TPD and $[2 \mathrm{~F}] \mathrm{T}$ motifs along the main chain may achieve the appropriate energy gap and electron-transport patterns to be used as the electron-transport component in nonfullerene BHJ devices. ${ }^{[49]}$

In this contribution, we report on the design approach, material properties and efficiencies in BHJ solar cells of a set of two analogous TPD/[2F]T-based polymer acceptors - with a specific look on how the introduction of a third electron-deficient motif, namely 2,1,3-benzothiadiazole (BT) ${ }^{[50-52]}$ can impact the optical, electronic and charge transport properties of the corresponding polymer. Comparing the two analogues shown in Chart 1 (P2TPD[2F]T and P2TPDBT[2F]T), we find that the introduction of BT in the polymer main chain narrows the optical gap $\left(E_{\mathrm{opt}}\right)$ : from $c a$. $1.9 \mathrm{eV}$ in $\mathrm{P} 2 \mathrm{TPD}[2 \mathrm{~F}] \mathrm{T}$, to $1.7 \mathrm{eV}$ in $\mathrm{P} 2 \mathrm{TPDBT}[2 \mathrm{~F}] \mathrm{T}$; extending the polymer optical absorption to longer wavelengths (by $c a .70 \mathrm{~nm}$ ). These empirical results are supported by density functional theory (DFT) calculations (at the tuned $\omega \mathrm{B} 97 \mathrm{X}-\mathrm{D} / 6-31 \mathrm{G}(\mathrm{d}, \mathrm{p}$ ) level), examining the polymer $E_{\text {opt }}$ values and the effect of repeat unit composition on main-chain 


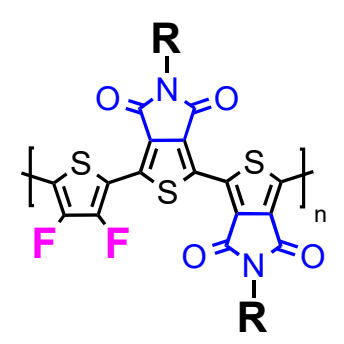

(a) P2TPD[2F]T

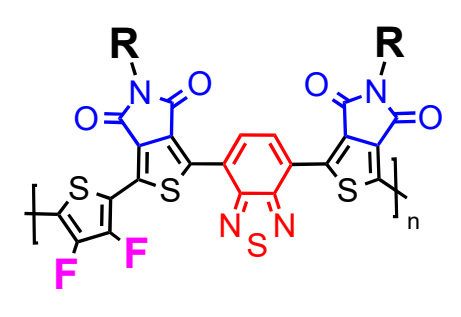

(b) P2TPDBT[2F]T
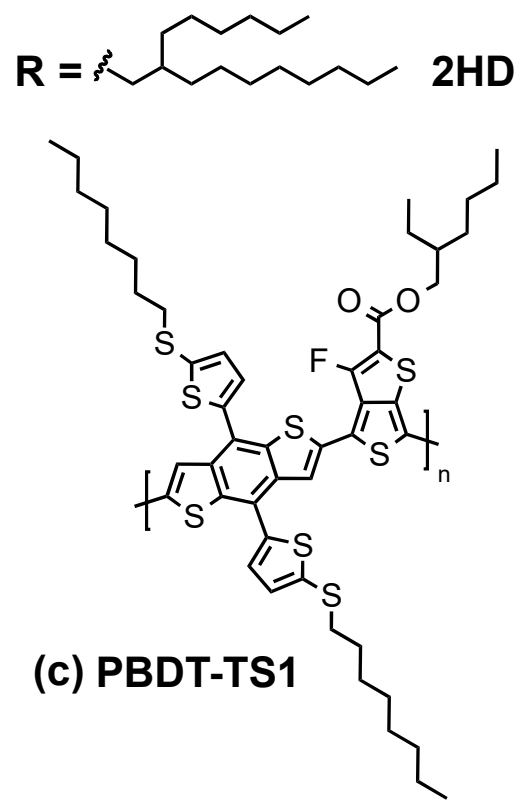

Chart 1. Chemical structures of the TPD- and [2F]T-based polymer acceptors (a) P2TPD[2F]T, (b) P2TPDBT[2F]T); (c) chemical structure of the polymer donor PBDT-TS1 (model system).

conformational patterns. In BHJ devices with the low-bandgap polymer donor PBDT-TS1 (poly[4,8-bis(5-(octylthio)thiophen-2-yl)benzo[1,2-b;4,5-b']dithiophene-2,6-diyl-alt-(4-(2ethylhexyl)-3-fluorothieno[3,4-b]thiophene-)-2-carboxylate-2-6-diyl)) commonly used with fullerenes (here taken as a model system; see Chart 1), we find that the concurrent rise in electron mobility from $2.4 \times 10^{-7}$ to $6.1 \times 10^{-5} \mathrm{~cm}^{2} \mathrm{~V}^{-1} \mathrm{~s}^{-1}$ in optimized blend BHJ films (and 


\section{WILEY-VCH}

reduced carrier imbalance) contributes to the significant device PCE variations observed: as high as $c a .4 .8 \%$ for $\mathrm{P} 2 \mathrm{TPDBT}[2 \mathrm{~F}] \mathrm{T}$, compared with $c a .2 .6 \%$ (max.) for the $\mathrm{P} 2 \mathrm{TPD}[2 \mathrm{~F}] \mathrm{T}$ counterpart. Optimized P2TPDBT[2F]T-based BHJ devices combine a large open-circuit voltage $\left(V_{\mathrm{OC}}\right)$ of $c a .1 .0 \mathrm{~V}$ and high short-circuit current values $\left(J_{\mathrm{SC}}\right)$ of $c a .11 .0 \mathrm{~mA} \mathrm{~cm}{ }^{-2}$. Importantly, both TPD/[2F]T-based polymer analogues can be used as fullerene alternatives in BHJ solar cells, and the narrow-gap P2TPDBT[2F]T derivative shows significant promises as a nonfullerene acceptor for efficient all-polymer BHJ solar cells.

\section{Results and Disscusion}

\subsection{Design, Synthesis and Material Properties}

The design of polymer acceptors from electron-deficient motifs - as alternatives to fullerenes - has practical implications that span synthetic accessibility and potentially low synthetic costs compared with those involved in the synthesis of PCBM analogues ${ }^{[53]}$ (subject to extensive purification protocols). The ability to tune the optoelectronic properties (i.e., electron affinities, EAs; ionization potentials, IPs; spectral absorption; etc.) of polymer acceptors by design is another clear benefit given that fullerene derivatizations either have modest effects on their optoelectronics or tend to result in lower material performance in BHJ solar cells with polymer donors. As stated earlier, thieno[3.4-c]pyrrole-4,6-dione (TPD) can be a building motif of particular interest given the modularity of the imide site to which various solubilizing side-chain substituents can be appended. ${ }^{[36,43-44]}$ In the design of polymer donors for high-efficiency BHJ 


\section{WILEY-VCH}

solar cells with PCBM acceptors, distinct side chain patterns can induce significant variations in BHJ morphology and intermolecular interactions between donor and acceptor counterparts; ${ }^{[36]}$ turning to polymer acceptors, those effects may also play an important role and influence material performance. Given that both $\mathrm{TPD}^{[36-47]}$ and 3,4-difluorothiophene $([2 \mathrm{~F}] \mathrm{T})^{[48-49,54-55]}$ motifs can effectively increase the IP and EA values when involved in polymer main chains, the combination of these two units along the same backbone can be thought of as a relevant design approach to fullerene alternatives.

To characterize the electronic structure of the two TPD/[2F]T-based material systems shown in Chart $1(\mathrm{P} 2 \mathrm{TPD}[2 \mathrm{~F}] \mathrm{T}$ and P2TPDBT[2F]T), we turned to Density Functional Theory (DFT), using modern long-range corrected functionals including dispersion effects. DFT analyses at that level of theory can also probe reliably for backbone planarity effects, while anticipating possible steric hindrance between substituted thiophene motifs - here TPD and $[2 \mathrm{~F}] \mathrm{T}$ - and other comonomers combined within the same backbone. ${ }^{[56-59]}$ The calculations were performed at the tuned $\omega \mathrm{B} 97 \mathrm{X}-\mathrm{D} / 6-31 \mathrm{G}(\mathrm{d}, \mathrm{p})$ level of theory, which ensures a robust description of wavefunction localization / delocalization effects along extended $\pi$-conjugated chains. The range-separation parameter $(\omega)$ in $\omega \mathrm{B} 97 \mathrm{X}-\mathrm{D}$, was optimized following the ionization potential (IP) tuning procedure ${ }^{[57-59]}$ Converged $\omega$ values in the polymer limit for P2TPD[2F]T, P2TPDBT[2F]T, and PBDT-TS1 are 0.11, 0.11, $0.09 \mathrm{Bohr}^{-1}$ respectively (we recall that $0.20 \mathrm{Bohr}^{-1}$ is the default $\omega$ value in $\omega \mathrm{B} 97 \mathrm{X}-\mathrm{D}$ and $1 \mathrm{Bohr}$ is equal to $0.529 \AA$ ). Using these converged $\omega$ values, we 


\section{WILEY-VCH}

calculated the IP and EA values of oligomers of increasing length. Figure 1a shows how the (extrapolated) IP and EA of P2TPD[2F]T and P2TPDBT[2F]T align with those of the model
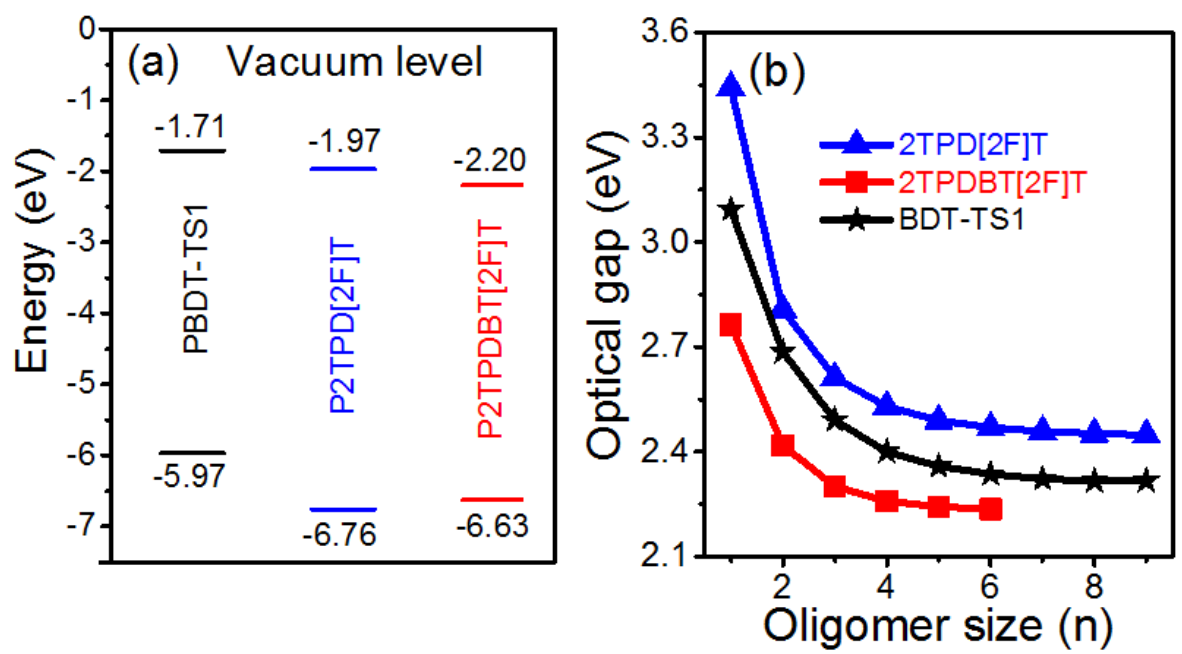

Figure 1. (a) Ionization potential (IP) and electron affinity (EA) values for the polymer limit at the tuned- $\omega \mathrm{B} 97 \mathrm{X}-\mathrm{D} / 6-31 \mathrm{G}(\mathrm{d}, \mathrm{p}) / / \omega \mathrm{B} 97 \mathrm{X}-\mathrm{D} / 6-31 \mathrm{G}(\mathrm{d}, \mathrm{p})$ level of theory. (b) Evolution of the optical gap vs. oligomer size for the P2TPD[2F]T, P2TPDBT[2F]T and PBDT-TS1 chains;

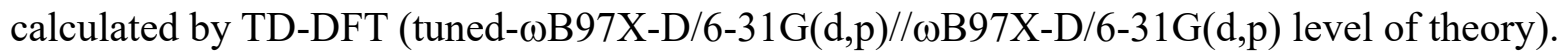

polymer PBDT-TS1; the offset between the EAs of the donor and acceptor counterparts is found to increase when BT is introduced as a third electron-deficient motif. Importantly, these calculations indicate that both TPD/[2F]T-based polymer analogues may be used as fullerene alternatives in BHJ solar cells, with P2TPDBT[2F]T expected to possess a narrower optical gap than its $\mathrm{P} 2 \mathrm{TPD}[2 \mathrm{~F}] \mathrm{T}$ counterpart. The excited-state characteristics were calculated using the time-dependent DFT (TD-DFT) approach. Figure 1b illustrates the convergence of the optical 


\section{WILEY-VCH}

properties in increasingly long oligomers composed of $2 \mathrm{TPD}[2 \mathrm{~F}] \mathrm{T}$ and $2 \mathrm{TPDBT}[2 \mathrm{~F}] \mathrm{T}$ repeat units; a similar evolution is reported for the polymer donor PBDT-TS1 (cf. additional experimental details in the Supporting Information, SI). Our analyses indicate that the optical gaps of the oligomers level off after 6 to 8 repeat units. The corresponding optical gaps for the polymer chains (here taken as isolated, i.e., with no explicit account of the surrounding medium) extrapolate to $2.45 \mathrm{eV}$ in P2TPD[2F]T, $2.24 \mathrm{eV}$ in P2TPDBT[2F]T, and $2.32 \mathrm{eV}$ in PBDT-TS1.

Prior to synthesizing the TPD/[2F]T-based polymer analogues, examining the conformational effects between electron-deficient motifs along the polymer main chain can provide important insights on effective conjugation and backbone planarity. Torsion potentials related to the rotation of adjacent motifs in the $\mathrm{P} 2 \mathrm{TPD}[2 \mathrm{~F}] \mathrm{T}$ and $\mathrm{P} 2 \mathrm{TPDBT}[2 \mathrm{~F}] \mathrm{T}$ repeat units were computed at an interval of $5^{\circ}$ by fixing the dihedral angle and relaxing all other geometrical degrees of freedom; the data are overlaid in Figure 2. The torsion potentials for TPD/[2F]T and TPD/TPD (Figure 2a) as well as for TPD/BT and TPD/[2F]T (Figure 2b) have two minima, with the one for coplanar chains $\left(180^{\circ}\right.$ dihedral angle) being more stable than the one at $45^{\circ}$. The barrier heights separating the two minima, starting from the optimal $180^{\circ}$ conformation, are over $3 \mathrm{kcal} / \mathrm{mol}$ for both chains. Such energetic barriers are expected to impede inter-conversion between "syn" and "anti" conformers at room temperature (thermal energy at $300 \mathrm{~K}=0.6 \mathrm{kcal} / \mathrm{mol}$ ). Hence, coplanar "anti" conformations are predicted to be the preferred conformations in the two polymers. 


\section{WILEY-VCH}
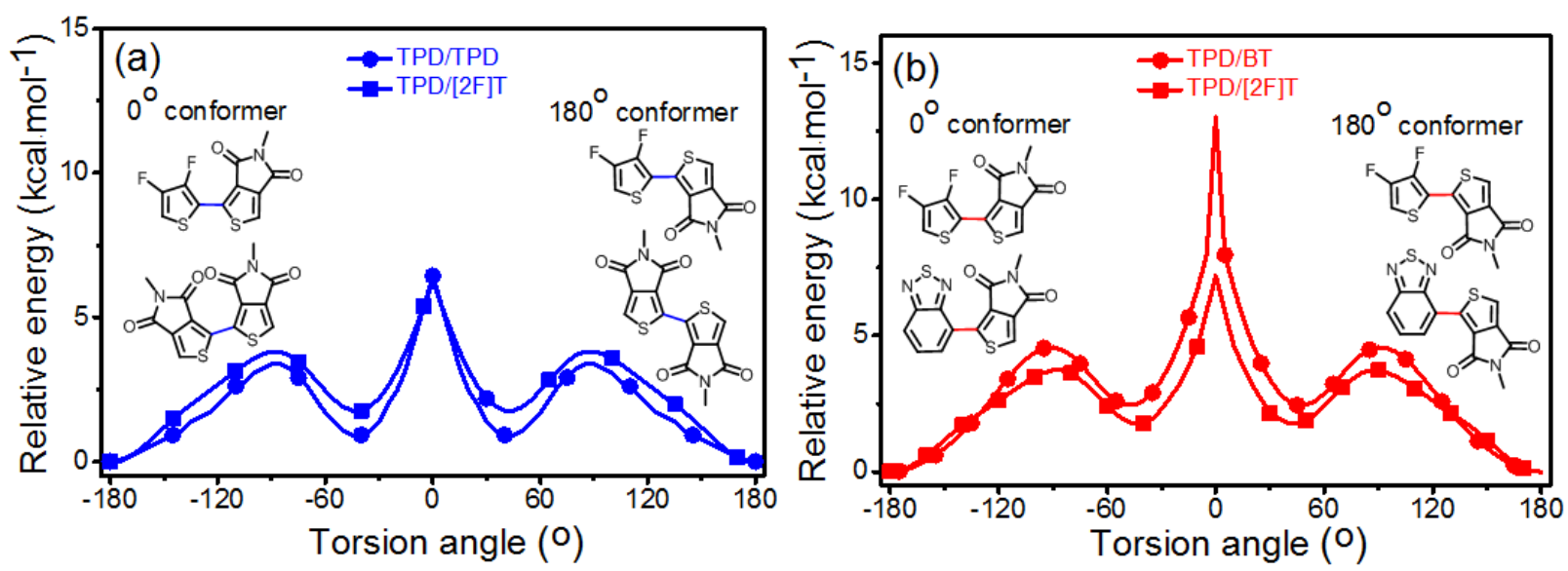

Figure 2. Torsion potentials related to the rotation of the TPD motifs with respect to the TPD, BT, and [2F]T motifs in (a) P2TPD[2F]T, and (b) P2TPDBT[2F]T; relative energies determined at the tuned- $\omega \mathrm{B} 97 \mathrm{X}-\mathrm{D} / 6-31 \mathrm{G}(\mathrm{d}, \mathrm{p})$ level (further details are provided in the SI). The cusp in the torsion potential curves is related to the specific steric interactions between oxygen and fluorine atoms at $0^{\circ}$.

Figure 3 depicts the DFT-calculated tuned- $\omega$ B97X-D natural transition orbitals (with largest weight) for the $\mathrm{S}_{0}$ to $\mathrm{S}_{1}$ transition of $\mathrm{P} 2 \mathrm{TPD}[2 \mathrm{~F}] \mathrm{T}$ (octamer used for the representation; cf. expanded structure in SI) and P2TPDBT[2F]T (hexamer used for the representation). The excitation (prior to any geometry relaxation in the $\mathrm{S}_{1}$ state) is seen in both cases to delocalize over $c a .3$ repeat units. We note that here, in order to reduce computational time, the side chains were considered to be simple methyl groups since those do not impact the optical properties of the main chains. ${ }^{[56-59]}$ 


\section{WILEY-VCH}

(a)
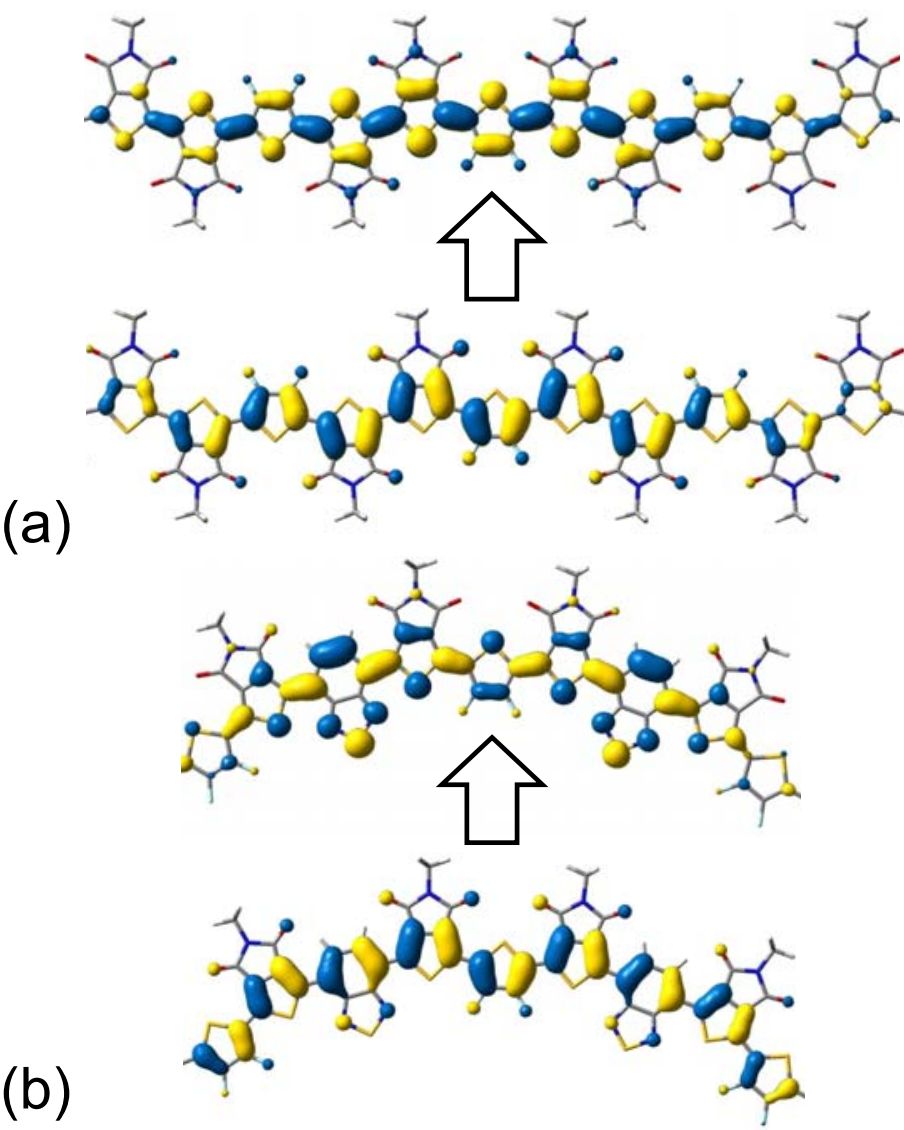

Figure 3. TD-DFT (tuned- $\omega$ B97X-D) natural transition orbitals (bottom: hole wavefunction; top: electron wavefunction) with the largest contribution to the $\mathrm{S}_{0} \rightarrow \mathrm{S}_{1}$ transition in: (a) the $2 \mathrm{TPD}[2 \mathrm{~F}] \mathrm{T}$ octamer and (b) the 2TPDBT[2F]T hexamer; for the sake of clarity, only the central parts of the oligomers are illustrated (full representations are given in the SI, Figures S4 and S8).

Based on these DFT predictions, the repeat-unit structures depicted in Chart 1 may indeed lead to novel polymer acceptor candidates if the appropriate synthetic protocol can be developed. Scheme 1 outlines the key steps in the synthesis of the 2TPD (4) and 2TPDBT (6) monomers (adapted from previously reported methods) ${ }^{[45]}$ and their polymerization with $[2 \mathrm{~F}] \mathrm{T}$ as 


\section{WILEY-VCH}

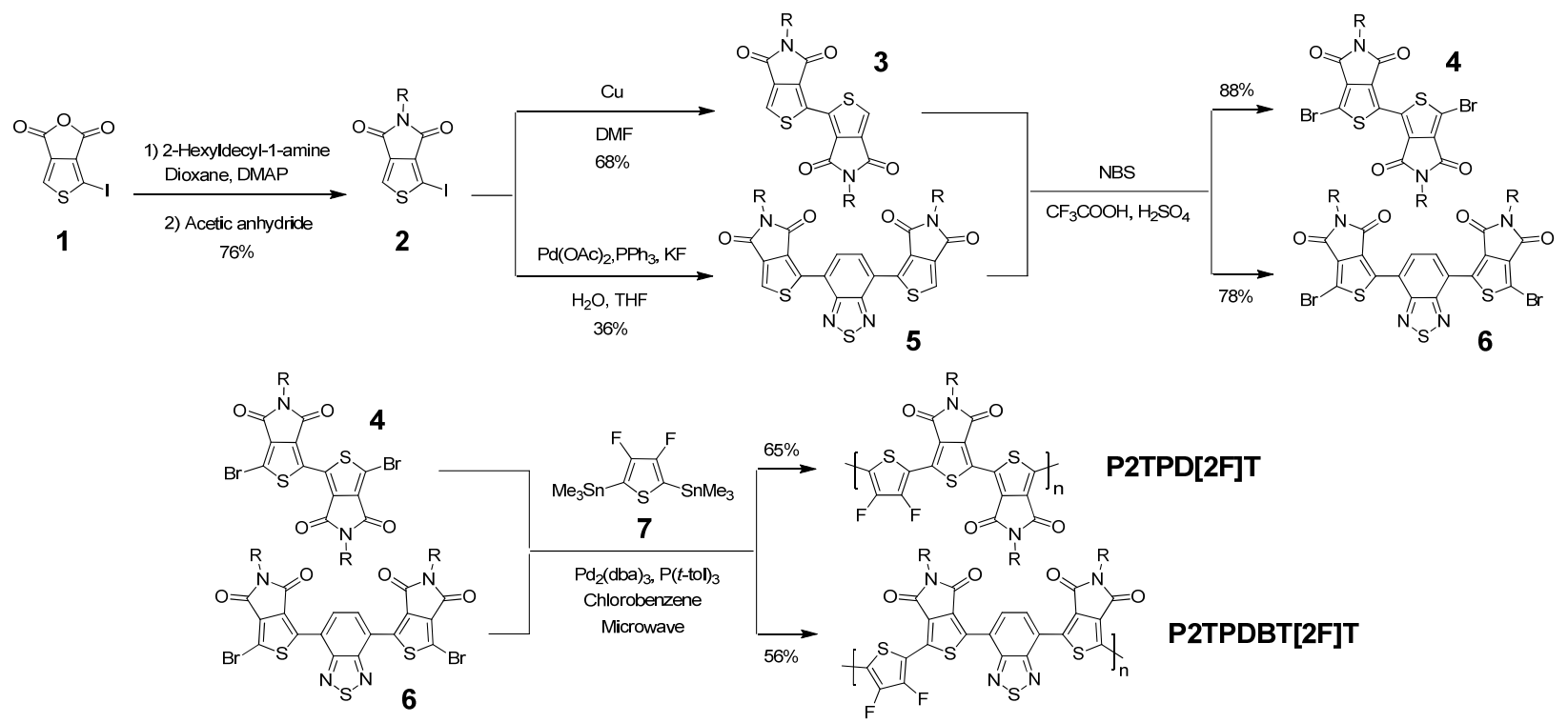

Scheme 1. Synthesis of the 2TPD and 2TPDBT monomers, and the polymer acceptors P2TPD[2F]T and P2TPDBT[2F]T.

co-monomer, yielding the polymer analogues P2TPD[2F]T and P2TPDBT[2F]T. The unsymmetrical imide intermediate 2 is obtained in a two-step reaction from 4-iodothieno[3,4c] furan-1,3-dione (1) (overall yield: 76\%); ${ }^{[45]}$ cf. experimental details in the SI. Copper-mediated Ullmann coupling conditions are used to produce intermediate (3) (68\%), which is then converted to the 2TPD monomer (4) in a relatively high-yielding bromination step (88\%). Alternatively, palladium-mediated Suzuki coupling conditions between the unsymmetrical imide intermediate (2) and 2,1,3-benzothiadiazole-4,7-bis(boronic acid pinacol ester) affords the 2TPDBT monomer (5), which can be subjected to the same bromination protocol. While the DFT calculations indicate that the two TPD units in the 2TPD monomer are predicted to adopt a 


\section{WILEY-VCH}

coplanar, "anti" conformation (see Figures 2 and 3), the two TPD units appended to BT in 2TPDBT are expected to be "syn" with respect to one another, noting that coplanarity is maintained as BT is introduced between the two TPD units (see Figures 2 and 3). Here, we note that prior work and single-crystal structure analyses have shown that both monomers are indeed coplanar, in agreement with the DFT-predicted conformations. ${ }^{[45]}$ Backbone planarity favors $\pi$ electron delocalization and promotes large wavefunction overlaps between neighboring chains, which can in turn benefit charge transport in thin-film devices, including BHJ solar cells. ${ }^{[5,60]}$ The polymer analogues $\mathrm{P} 2 \mathrm{TPD}[2 \mathrm{~F}] \mathrm{T}$ and $\mathrm{P} 2 \mathrm{TPDBT}[2 \mathrm{~F}] \mathrm{T}$ (Chart 1) were synthesized via a microwave-assisted Stille cross-coupling polymerization $\left(150^{\circ} \mathrm{C}\right.$ in chlorobenzene $(\mathrm{CB})$, for $\left.1 \mathrm{~h}\right)$ in order to control polymer growth and molecular weight (MW), while minimizing reaction times. The TPD/[2F]T-based polymers were prepared by Pd-mediated Stille cross-coupling polymerization (cf. synthetic methods in SI), and purified using established protocols: ${ }^{[36]}$ using the strongly complexing ligand N,N-diethyl-2-phenyldiazenecarbothioamide to remove palladium residues, and subjecting the polymers to Soxhlet extractions (methanol, dichloromethane) to remove short-chain oligomers, affording batches of comparable numberaverage molecule weight $\left(\mathrm{P} 2 \mathrm{TPD}[2 \mathrm{~F}] \mathrm{T}: \mathrm{M}_{\mathrm{n}}=22.6 \mathrm{kDa}\right.$ and P2TPDBT[2F]T: $\left.\mathrm{M}_{\mathrm{n}}=23.1 \mathrm{kDa}\right)$ and polydispersity indices $(\mathrm{PDI}=2.0 / 2.3$, respectively). $\mathrm{MW}$ effects have been shown to impact charge transport and polymer efficiency in BHJ solar cells. ${ }^{[61]}$ The two polymers were found to be soluble in common organic solvents such as chloroform (CF), 1-chlorobenzene (CB), 1,2- 


\section{WILEY-VCH}

dichlorobenzene (o-DCB), and toluene (appropriate solvents in the solution-processing of BHJ solar cells with established polymer donors, such as PBDT-TS1 shown in Chart 1). For consistency in this study, the same 2-hexyldecyl (2HD) branched alkyl side chains were appended to the two analogous polymer backbones, and the solubility of the resulting polymers in the aforementioned solvents was found to be comparable. Further synthetic details and structural analyses including ${ }^{1} \mathrm{H}$ NMR, ${ }^{19} \mathrm{~F}$ NMR, ${ }^{13} \mathrm{C}$ NMR for the key intermediates and polymers are provided in the SI.

The thermal properties of the two analogous polymers P2TPD[2F]T and P2TPDBT[2F]T were investigated by thermogravimetric analysis (TGA) and differential scanning calorimetry (DSC) under nitrogen atmosphere; results shown in Figure S11-12. The data shows that the polymers are thermally stable until ca. $350{ }^{\circ} \mathrm{C}\left(\mathrm{ca} .5 \%\right.$ weight loss observed at $361{ }^{\circ} \mathrm{C}$, and $373{ }^{\circ} \mathrm{C}$, respectively), and are thus sufficiently stable to undergo post-processing thermal annealing (which can be part of device optimization procedures) and standard solar cell device operation conditions. No glass transition, crystallization or melting peak is obviously observed in DSC measurement between $20^{\circ} \mathrm{C}$ and $250^{\circ} \mathrm{C}$.

The normalized thin-film UV-vis absorption spectra of P2TPD[2F]T and P2TPDBT[2F]T and that of the polymer donor PBDT-TS1 (model system later used in the BHJ solar cell device study) are superimposed in Figure 4a; the temperature-dependent solution UV-vis spectra are provided in Figure S13. As shown in Figure 4a, the spectral absorption of P2TPD[2F]T falls in 


\section{WILEY-VCH}
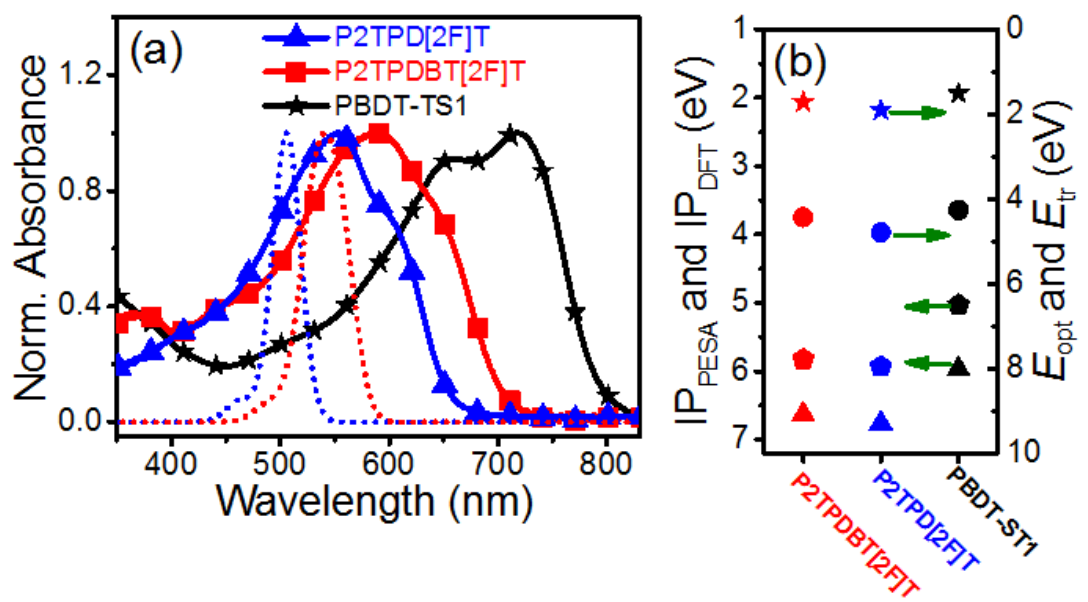

Figure 4. (a) Superimposed, normalized UV-Vis optical absorption spectra of polymer donor PBDT-TS1 and the polymer acceptors systems (P2TPD[2F]T, P2TPDBT[2F]T) (neat films), the dotted curve depicts the DFT-inferred optical spectrum of a the 2TPD[2F]T octamer (blue) and 2TPDBT[2F]T hexamer (red). (b) PESA-estimated ionization potentials (IPPESA, pentagons), optical gaps ( $E_{\mathrm{opt}}$, stars) estimated from the onset of the UV-Vis absorption spectra (films), ionization potentials calculated at the tuned- $\omega B 97 X-D / 6-31 G(d, p) / / \omega B 97 X-D / 6-31 G(d, p)$ level of theory (IPDFT, triangles), and transport gaps calculated at the same level ( $E_{\mathrm{tr}}$, circles) for the three polymers.

the visible range: $400-650 \mathrm{~nm}$, peaking at $c a .553 \mathrm{~nm}$, with an onset of absorption at $c a .650 \mathrm{~nm}$ from which an optical bandgap $\left(E_{\mathrm{opt}}\right)$ value of $c a .1 .9 \mathrm{eV}$ can be inferred. In comparison, P2TPDBT[2F]T has its absorption spectrum red-shifted by $c a .70 \mathrm{~nm}$ (peaking at $c a .590 \mathrm{~nm}$ ) and an onset of absorption at $c a .720 \mathrm{~nm}$ from which a narrower $E_{\text {opt }}$ value of $c a .1 .7 \mathrm{eV}$ can be estimated. The net bathochromic shift observed with P2TPDBT[2F]T can be expected to result 


\section{WILEY-VCH}

from the more pronounced electron-deficient character of BT (inducing larger EAs; i.e. lowering the LUMO of the polymer) compared with that of the TPD and [2F]T motifs. Our DFT calculations (see Table 1; overview in Figure 1b) indicate that P2TPDBT[2F]T undergoes an IP decrease (HOMO destabilization) by $0.13 \mathrm{eV}$ and an EA increase (LUMO stabilization) by 0.23 $\mathrm{eV}$ upon incorporation of the third electron-deficient BT motif. Figure 4a further emphasizes the extent of spectral complementarity between the TPD/[2F]T-based polymers and the polymer donor PBDT-TS1 (onset of absorption at $c a .800 \mathrm{~nm}$ ); $;^{[62]}$ absorption complementarity is expected to impact favorably the photon-to-current conversion efficiency and, in turn, the shortcircuit current $\left(J_{\mathrm{SC}}\right)$ in BHJ solar cells.

The temperature-dependent solution UV-vis spectra shown in Figure S13 indicate that temperature has a negligible effect on the main absorption bands of $\mathrm{P} 2 \mathrm{TPD}[2 \mathrm{~F}] \mathrm{T}$, P2TPDBT[2F]T and the polymer donor PBDT-TS1, suggesting that the polymers are not prone to pronounced pre-aggregation behaviors in solution (yet ordered aggregates may still form during the film-casting step). In parallel, Figure S14 shows that the solution and neat film spectra (Figure 4a) are nearly superimposable, with only a slight bathochromic shift of $c a .5-10 \mathrm{~nm}$ observed on going from solution to films. This observation implies that ordered polymer aggregates are not forming during the casting step.

The IPs of the P2TPD[2F]T, P2TPDBT[2F]T, and PBDT-TS1 polymers were determined via photoelectron spectroscopy in air (PESA) (cf. details in the SI): ca. $5.93 \mathrm{eV}$ for P2TPD[2F]T, $c a$. 


\section{WILEY-VCH}

$5.82 \mathrm{eV}$ for P2TPDBT[2F]T, and $c a .5 .03 \mathrm{eV}$ for PBDT-TS1; see Figure S15 and Table 1. The expectedly large IP values estimated for the TPD/[2F]T-based polymers are within range of those commonly inferred for fullerene acceptors ( $c a .5 .9 \mathrm{eV}$ by PESA), and follow the trend set by the IP energies (for the isolated chains) of $c a .6 .76 \mathrm{eV}$ and $6.63 \mathrm{eV}$, respectively, inferred from the DFT calculations (Table 1; cf. experimental details in SI). Table 1 provides further details, including electrochemically-estimated IPs and EAs (cf. experimental details in the SI), and transport gap estimates obtained from the DFT calculations. Figure S16 shows the oxidation and reduction scans from which the electrochemically estimated IPs and EAs were inferred: $c a .5 .97$ and $4.05 \mathrm{eV}$ for P2TPD[2F]T, ca. 5.90 and $4.14 \mathrm{eV}$ for P2TPDBT[2F]T (vs. 5.52 and $3.85 \mathrm{eV}$ for PBDT-TS1), respectively. The electrochemically estimated EA values are within range of those estimated in earlier reports for common fullerene acceptors such as $\mathrm{PC}_{61} \mathrm{BM}$ and $\mathrm{PC}_{71} \mathrm{BM}$ (4.1$4.3 \mathrm{eV})^{[15-16]}$ and for PDI/NDI-based polymer acceptors. ${ }^{[18-29]}$ From Figure $4 \mathrm{~b}$ and Table 1, the expected IP- and EA-derived energy offsets for hole/electron transfer between P2TPDBT[2F]T and PBDT-TS1 are $c a .0 .38 \mathrm{eV}$ and $0.29 \mathrm{eV}$, respectively (estimated from the IP echem and EAechem values presented in Table 1); these values, which do not take account of interfacial effects, are significantly larger than the $0.1 \mathrm{eV}$ value arguably sufficient to promote efficient electron [hole] transfer at the donor-acceptor interface (a process that factually involves $\mathrm{S}_{1}$ and CT states). ${ }^{[63-67]}$

Table 1. Summary of optical and electronic parameters for the polymer donor PBDT-TS1 and polymer acceptors: P2TPD[2F]T, and P2TPDBT[2F]T.

\begin{tabular}{lllllllllll} 
Polymer & $\lambda_{\mathrm{abs}} / \mathrm{sol}$ & $\lambda_{\mathrm{abs}} / \mathrm{film}$ & $\mathrm{IPPESA}^{a}$ & $E_{\mathrm{opt}^{b}}$ & $\mathrm{IP}_{\mathrm{echem}^{c}}$ & $\mathrm{EA}_{\mathrm{echem}^{c}}$ & $\mathrm{IP}_{\mathrm{DFT}}{ }^{d}$ & $\mathrm{EA}_{\mathrm{DFT}}{ }^{d}$ & $E_{\mathrm{tr}^{d}}$ \\
\hline
\end{tabular}




\begin{tabular}{cccccccccc}
\hline & $(\mathrm{nm})$ & $(\mathrm{nm})$ & $(\mathrm{eV})$ & $(\mathrm{eV})$ & $(\mathrm{eV})$ & $(\mathrm{eV})$ & $(\mathrm{eV})$ & $(\mathrm{eV})$ & $(\mathrm{eV})$ \\
\hline PBDT-TS1 & 708 & 717 & 5.03 & 1.51 & 5.52 & 3.85 & 6.02 & 1.78 & 4.26 \\
P2TPD[2F]T & 554 & 553 & 5.93 & 1.91 & 5.97 & 4.05 & 6.76 & 1.97 & 4.79 \\
P2TPDBT[2F]T & 584 & 590 & 5.82 & 1.72 & 5.90 & 4.14 & 6.63 & 2.20 & 4.43 \\
\hline
\end{tabular}

${ }^{a}$ Estimated by photoelectron spectroscopy in air (PESA). ${ }^{b}$ Optical gaps estimated from the onset of the UV-vis absorption spectra (films). ${ }^{c}$ Estimated from cyclic voltammetry (CV) measurements; $\mathrm{IP}_{\text {echem }}=\mathrm{E}_{\text {onset,ox }}+5.1 \mathrm{eV}$ and $\mathrm{EA}_{\text {echem }}=\mathrm{E}_{\text {onset,red }}+5.1 \mathrm{eV}$ (absolute values).

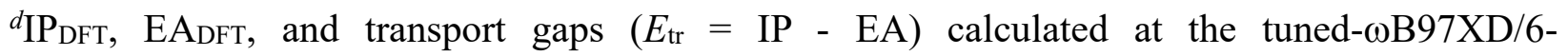
$31 \mathrm{G}(\mathrm{d}, \mathrm{p}) / / \omega \mathrm{B} 97 \mathrm{XD} / 6-31 \mathrm{G}(\mathrm{d}, \mathrm{p})$ level of theory.

\subsection{Device Testing and Characterizations}

Thin-film BHJ solar cells with the inverted device structure ITO/ZnO/PBDTTS1:Polymer_Acceptor/ $\mathrm{MoO}_{3} / \mathrm{Ag}$ (device area: $0.1 \mathrm{~cm}^{2}$ ) were fabricated and tested under AM1.5G solar illumination $\left(100 \mathrm{~mW} / \mathrm{cm}^{2}\right)$. The cells with optimized polymer donor and acceptor blend ratios of 1:2 (wt/wt) were cast from chloroform (CF) (cf. details in the SI; optimized active layer thicknesses: avg. $85 \mathrm{~nm}$ ). For comparison, the fullerene acceptor (here $\mathrm{PC}_{71} \mathrm{BM}$ ) based inverted $\mathrm{BHJ}$ solar cells were also fabricated from previously reported methods, ${ }^{[62]}$ and the performance were shown in Table 2. Figure 5a shows the current-voltage $(J-V)$ characteristics of optimized BHJ solar cells made with P2TPD[2F]T, P2TPDBT[2F]T and the polymer donor PBDT-TS1. As shown in Table 2 (cf. device statistics in Table S6), "as-cast" BHJ devices made from the polymer acceptors P2TPD[2F]T and P2TPDBT[2F]T achieve notable average PCE values of $c a .2 .1 \%$ and $3.6 \%$, respectively, a high $V_{\mathrm{OC}}$ of $c a .1 \mathrm{~V}$, but limited $J_{\mathrm{SC}}$ values of $<9 \mathrm{~mA} \mathrm{~cm}{ }^{-2}$. Meanwhile, thermally-annealed BHJ devices made with P2TPDBT[2F]T (optimized thermal annealing temperature at $80{ }^{\circ} \mathrm{C}, 10 \mathrm{~min}$; prior to $\mathrm{MoO}_{3} / \mathrm{Ag}$ 


\section{WILEY-VCH}

contact deposition) yield higher $J_{\mathrm{SC}}$ and fill-factor (FF) values of $c a .11 .0 \mathrm{~mA} / \mathrm{cm}^{2}$ and $44 \%$, respectively, reaching PCEs of up to $4.8 \%$ (avg. 4.6\%). In comparison, thermally-annealed BHJ devices made with $\mathrm{P} 2 \mathrm{TPD}[2 \mathrm{~F}] \mathrm{T}$ (same post-contact treatment) undergo only limited $J_{\mathrm{SC}}$ improvements and the estimated PCEs of up to 2.6\% (avg. 2.4\%) remain somewhat modest. Overall, BHJ solar cells made with P2TPDBT[2F]T achieve a stark $c a$. twofold PCE improvement over devices made with the analogous polymer P2TPD[2F]T. Interestingly, the high device $V_{\mathrm{OC}}$ values of $c a .1 .0 \mathrm{~V}$ obtained with the polymer acceptors P2TPD[2F]T and P2TPDBT[2F]T are larger than those obtained for the reference PBDT-TS1:PC 71 BM devices: $c a$. $0.8 \mathrm{~V}^{[62]}$ in spite of the comparable electrochemically-estimated EAs of the two polymer acceptors $(c a .4 .1 \mathrm{eV})$ and that of $\mathrm{PC}_{71} \mathrm{BM}$. Estimated from a $V_{\mathrm{OC}}$ of $c a .1 .0 \mathrm{~V}$, an energy loss ( $E_{\text {loss }}$ of $0.5 \mathrm{eV}$ (with $E_{\text {loss }}=\mathrm{E}_{\mathrm{opt}}{ }^{\mathrm{min}}-\mathrm{e} V \mathrm{OC}$, and $E_{\mathrm{opt}}{ }^{\mathrm{min}}$ the smallest optical gap of either donor and acceptor) represents one of the lowest reported values for all-polymer BHJ solar cells, ${ }^{[30]}$ noting that $E_{\text {loss }}$ values $\leqslant 0.5 \mathrm{eV}$ are especially difficult to achieve in fullerene-based BHJ devices. ${ }^{[66-68]}$

The notable differences in $J_{\mathrm{SC}}$ values achieved in optimized P2TPD[2F]T- and P2TPDBT[2F]T-based BHJ solar cells (Table 2) are emphasized in the $J$ - $V$ curves shown in Figure 5a, and reflected in the external quantum efficiency (EQE) spectra provided in Figure 5b; 

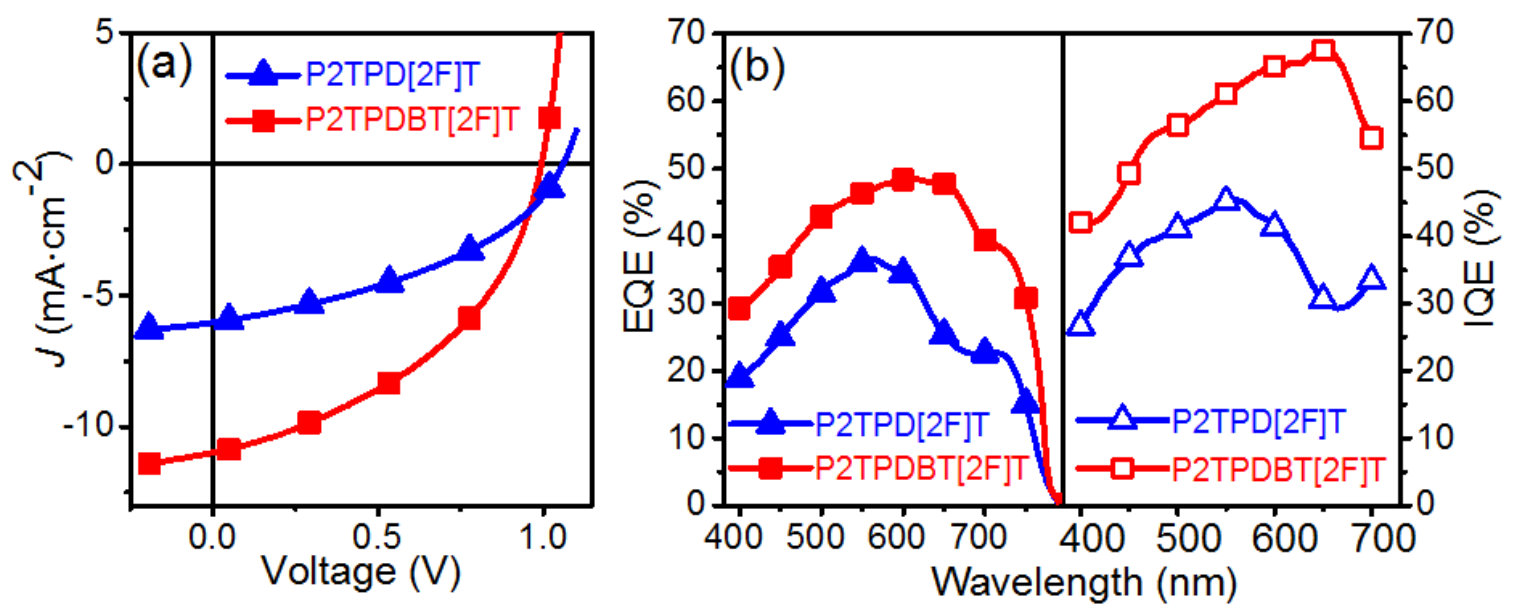

Figure 5. (a) Characteristic $J-V$ curves of optimized BHJ solar cells fabricated from P2TPD[2F]T and P2TPDBT[2F]T (cast from CF, thermally-annealed at $80{ }^{\circ} \mathrm{C}$ for $10 \mathrm{~min}$ ); AM1.5G solar illumination. (b) EQE and IQE spectra of the devices fabricated from the polymer acceptors and PBDT-TS1 (model system) under optimized conditions. Integrated EQEs are in agreement $\left( \pm 0.5 \mathrm{~mA} / \mathrm{cm}^{2} ; \pm 4 \%\right)$ with the $J_{\mathrm{SC}}$ values reported in Table 2 .

integrated EQEs $v s . J_{\mathrm{SC}}: \pm 0.5 \mathrm{~mA} / \mathrm{cm}^{2} ; \pm 4 \%$. The EQE spectra show a broad photo-response from 350 to $800 \mathrm{~nm}$, as expected given the spectral complementarity between the TPD/[2F]Tbased polymer acceptors and PBDT-TS1. Importantly, in both instances, the main contribution to the EQE arises from the polymer acceptor, noting that PBDT-TS1 extends the spectral response to longer, complementary wavelengths $(650-800 \mathrm{~nm})$ yet without the same prominent contribution. This observation underlines the effectiveness of the polymer acceptors in the incident photon-to-current conversion process. Another important observation relates to the spectral response of optimized P2TPDBT[2F]-based BHJ devices which is shown to be greater 


\section{WILEY-VCH}

than that of their P2TPD $[2 \mathrm{~F}] \mathrm{T}$ counterparts across the broad wavelength range $350-800 \mathrm{~nm}-$ with EQE values reaching $c a .50 \%$ at $600 \mathrm{~nm}$ (abs. max. of P2TPDBT[2F]T), and $>35 \%$ in the range 450-750 $\mathrm{nm}$ - indicating that both polymer acceptor- and donor-rich domains contribute more effectively to the photocurrent in P2TPDBT[2F]-based BHJ solar cells. The dependence on the effective optical absorption of the active layer is removed in comparing the internal quantum efficiency (IQE) spectra shown in Figure 5b (cf. experimental protocol and additional details in Figure S26 in the SI). While P2TPDBT[2F]-based BHJ devices show noticeably higher IQE values $>55 \%$ in the range $500-700 \mathrm{~nm}$ (peaking at $c a .70 \%$ at longer wavelengths where the absorption of P2TPDBT[2F]T prevails, with an offset of up to $c a$. 20\% relative to the EQE in the same wavelength range), both IQE spectra reflect significant recombination (and/or exciton quenching) losses at short-circuit (aspects discussed further in later sections).

Table 2. PV performance of the polymer acceptors P2TPD[2F]T and P2TPDBT[2F]T in inverted BHJ devices with PBDT-TS1 as the polymer donor. ${ }^{a, d}$

\begin{tabular}{ccccccc}
$\begin{array}{c}\text { Polymer } \\
\text { Acceptor }\end{array}$ & An. $^{\text {b }}$ & $\begin{array}{c}J_{\mathrm{SC}} \\
{\left[\mathrm{mA} / \mathrm{cm}^{2}\right]}\end{array}$ & $\begin{array}{c}V \text { OC } \\
{[\mathrm{V}]}\end{array}$ & $\begin{array}{c}\text { FF } \\
{[\%]}\end{array}$ & $\begin{array}{c}\text { Avg. PCE } \\
{[\%]}\end{array}$ & $\begin{array}{c}\text { Max. PCE } \\
{[\%]}\end{array}$ \\
\hline \multirow{2}{*}{ P2TPD[2F]T } & $\mathrm{N}$ & 5.7 & 1.0 & 40 & 2.1 & 2.2 \\
& $\mathrm{Y}$ & 6.0 & 1.1 & 41 & 2.4 & 2.6 \\
\hline \multirow{2}{*}{ P2TPDBT[2F]T } & $\mathrm{N}$ & 8.9 & 1.0 & 43 & 3.6 & 3.8 \\
& $\mathrm{Y}$ & 11.0 & 1.0 & 44 & 4.6 & 4.8 \\
\hline${\text { PC } 71 \mathrm{BM}^{\mathrm{e}}}^{\mathrm{e}}$ & $\mathrm{N}$ & 15.3 & 0.7 & 65 & 7.1 & 7.2
\end{tabular}

${ }^{a}$ Devices with optimized PBDT-TS1:Polymer_Acceptor ratio of 1:2 (wt/wt); solution-cast from chloroform (CF). ${ }^{b}$ Thermal annealing: $80{ }^{\circ} \mathrm{C}, 10 \mathrm{~min} .{ }^{\mathrm{c}}$ Average values across $>10$ devices (device area: $0.1 \mathrm{~cm}^{2}$ ). ${ }^{d}$ Additional device statistics, including standard deviations, are provided 


\section{WILEY-VCH}

in the SI (Figure S16). ${ }^{e}$ Device structure: ITO/ZnO/PBDT-TS1:PC $71 \mathrm{BM} / \mathrm{MoO}_{3} / \mathrm{Ag}$, the optimized BHJ photo active layer was prepared from previously reported methods. ${ }^{[62]}$

In some instances, morphological effects can explain stark differences in EQE and device efficiency characteristics because the extent of donor-acceptor interfaces and the carrier percolation network across the BHJ active layers impact charge separation and extraction efficiency. ${ }^{[25,70-71]}$ To examine the possible contribution of those effects on the respective EQEs, we turned to an examination of the BHJ morphologies obtained with the TPD/[2F]T-based polymer acceptors via bright-field transmission electron microscopy (TEM; cf. details in SI) and atomic-force microscopy (AFM, cf. details in SI). The TEM images provided in Figure 6a-b show relatively comparable morphologies at the scale of those examinations, suggesting that BHJ active layers obtained from the two polymer acceptors and the polymer donor PBDT-TS1 may form similar networks. The AFM images shown in Figure 6c-f (height and phase) indicate, however, that the root mean square (RMS) roughness vary between TPD/[2F]T-based BHJ active layers: P2TPDBT[2F]T, $0.55 \mathrm{~nm}$; P2TPD[2F]T, $2.80 \mathrm{~nm}$. This observation implies that the two polymers do not necessarily have the same nanoscale aggregation patterns in thin films, which may translate into different phase separation and carrier percolation patterns at the nanoscale; extraction and recombination effects are known to impact all-polymer BHJ solar cell performance (typically resulting in lower photocurrents and FFs). ${ }^{[25,70-71]}$ Figure 7 indicates that the photoluminescence (PL) quenching of PBDT-TS1 in the presence of P2TPDBT[2F]T (and 


\section{WILEY-VCH}
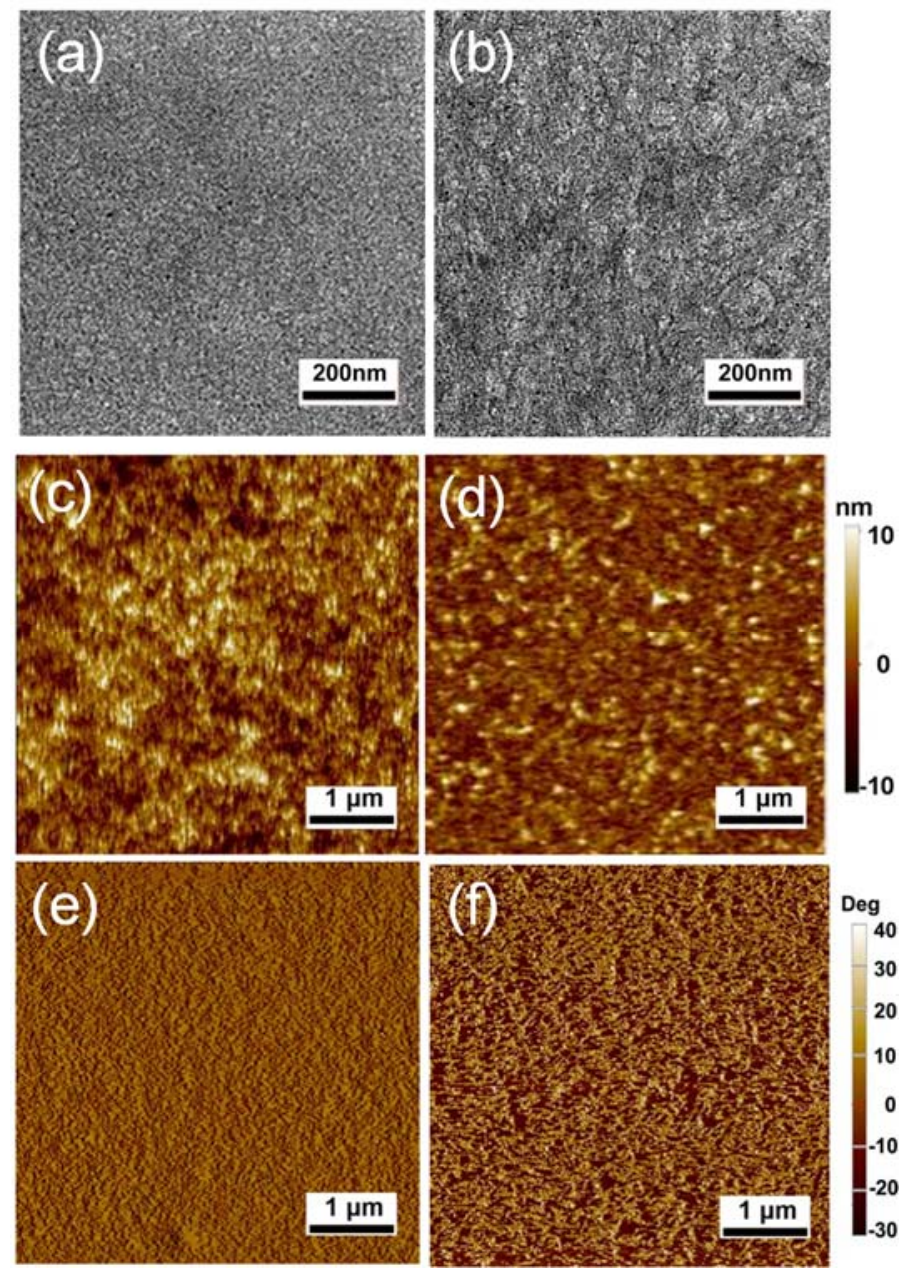

Figure 6. Bright-field TEM images for optimized BHJ active layers composed of (a) P2TPDBT[2F]T and (b) P2TPD[2F]T, and the polymer donor PBDT-TS1. AFM topography (cd) and phase (e-f) images (tapping mode) for optimized BHJ active layers composed of PBDTTS1 and the polymer acceptors (b, e: P2TPDBT[2F]T, d, f: P2TPD[2F]T). Root mean square (RMS) roughness: P2TPDBT[2F]T, $0.55 \mathrm{~nm}$; P2TPD[2F]T, $2.80 \mathrm{~nm}$.

vice-versa) is rather effective (yet not complete), with quenching efficiencies $>90 \%$ achieved in optimized donor-acceptor BHJ thin films. However, PL quenching efficiencies in blend films 

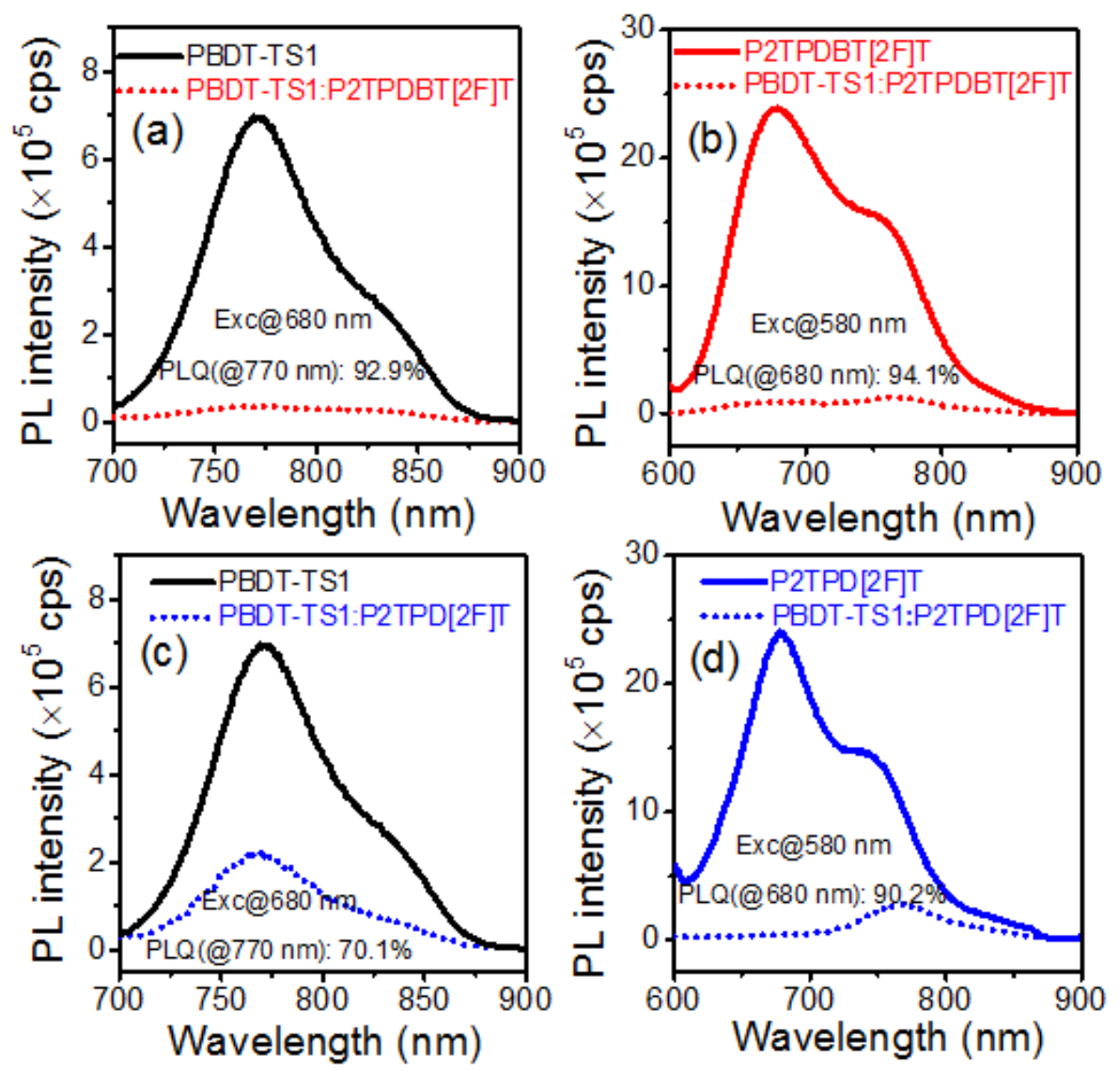

Figure 7. Photoluminescence (PL) quenching of PBDT-TS1 and the polymer acceptor analogues $\mathrm{P} 2 \mathrm{TPD}[2 \mathrm{~F}] \mathrm{T}$ and $\mathrm{P} 2 \mathrm{TPDBT}[2 \mathrm{~F}] \mathrm{T}$ in neat films (solid lines), and in the presence of the donor/acceptor counterpart (dashed lines) as in optimized BHJ thin films. (a) PBDTTS1:P2TPD[2F]T, excitation at $580 \mathrm{~nm}$; (b) PBDT-TS1:P2TPD[2F]T, excitation at $680 \mathrm{~nm}$; (c) PBDT-TS1:P2TPDBT[2F]T, excitation at $580 \mathrm{~nm}$; (d) PBDT-TS1:P2TPDBT[2F]T, excitation at $680 \mathrm{~nm}$.

of $\mathrm{P} 2 \mathrm{TPD}[2 \mathrm{~F}] \mathrm{T}$ and PBDT-TS1 is less quantitative, with a modest $70 \%$ quenching estimated in probing PBDT-TS1-rich domains; the UV-vis absorption and PL spectra of the polymer donor 


\section{WILEY-VCH}

and acceptors lying in regions of distinct wavelengths, the donor and acceptor components can be individually excited at different wavelengths (here $680 \mathrm{~nm}$ and $580 \mathrm{~nm}$, respectively). This observation implies that $\mathrm{P} 2 \mathrm{TPD}[2 \mathrm{~F}] \mathrm{T}$-based $\mathrm{BHJ}$ active layers are limited by the efficiency of exciton diffusion to the donor-acceptor interfaces, in line with the lower device photocurrents discussed earlier from the $J V / \mathrm{EQE}$ characteristics of optimized BHJ solar cells (Figure 5, Table 2). In parallel, these results emphasize that both electron and hole transfers are occurring more effectively in P2TPDBT[2F]T-based BHJ active layers, in agreement with the EQE/IQE spectra shown in Figure 5b (reflecting the photoinduced charge generation at short-circuit).

Subtle morphological differences between BHJ thin films can induce distinct charge transport patterns, impacting the figures of merit of solar cell devices. ${ }^{[25,69-71]}$ To examine carrier effects, we estimated the hole mobilities of PBDT-TS1 and electron mobilities of P2TPD[2F]T and P2TPDBT[2F]T in optimized BHJ thin films; estimates inferred from the space charge limited current (SCLC) model (cf. experimental details in the SI). Hole-only diodes with the configuration ITO/PEDOT:PSS/PBDT-TS1:Polymer_Acceptor/MoO $/ \mathrm{Mg}_{3} / \mathrm{Ag}$ and electron-only diodes with the configuration ITO/ZnO/PBDT-TS1:Polymer_Acceptor/Ca/Al (device area: 0.1 $\mathrm{cm}^{2}$ ) were fabricated for these measurements and analyzed in the dark. Figure 8 shows the dark current densities of the optimized BHJ thin films in the carrier-selective diodes as a function of applied effective field. Our analyses indicate that the zero-field hole mobilities of the PBDTTS1:Polymer_Acceptor blends fall within the same range, with average estimated values of 
$3.0 \times 10^{-4}$ and $3.1 \times 10^{-4} \mathrm{~cm}^{2} \mathrm{~V}^{-1} \mathrm{~s}^{-1}$ obtained with P2TPD[2F]T and P2TPDBT[2F]T, respectively (see Table 3). The $J-V$ curves of the electron-only diodes made with the PBDTTS1:Polymer_Acceptor blends followed Poole-Frenkel-type mobility fits (electric-field activated) of the form $\mu(\mathrm{F})=\mu_{0} \exp \left(\gamma \mathrm{F}^{1 / 2}\right)$, where $\mu_{0}$ is the zero field mobility, $\gamma$ is the Poole-Frenkel slope, and F is the electric field. In turn, the zero-field electron mobilities of the PBDT-TS1:Polymer_Acceptor blends were estimated to be $2.4 \times 10^{-7}$ and $6.1 \times 10^{-5} \mathrm{~cm}^{2} \mathrm{~V}^{-1} \mathrm{~s}^{-1}$ with P2TPD[2F]T and P2TPDBT[2F]T, respectively (see Table 3); results indicating that P2TPDBT[2F]T-based BHJ devices transport electrons significantly more effectively than their
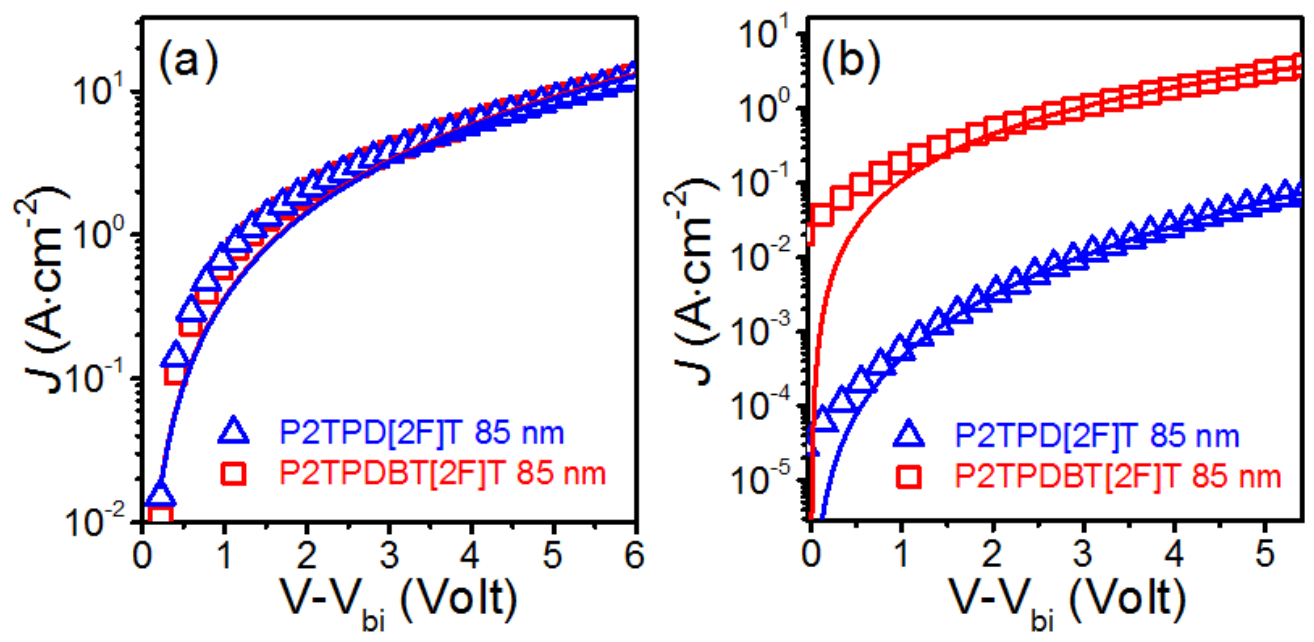

Figure 8. Experimental dark current densities as a function of effective electric field for (a) holeonly diodes (ITO/PEDOT:PSS/PBDT-TS1:Polymer_Acceptor/MoO$/ \mathrm{Ag}$ ); here, $V_{\mathrm{bi}}=0$ (flat band pattern formed by PEDOT:PSS and $\mathrm{MoO}_{3}$ ) and (b) electron-only diodes (ITO/ZnO/PBDTTS1:Polymer_Acceptor/Ca/Al $)$ made with optimized BHJ thin films $\left(V_{b i}=1.5 \mathrm{~V}\right)$ with 


\section{WILEY-VCH}

P2TPD $[2 \mathrm{~F}] \mathrm{T}$ and P2TPDBT[2F]T as polymer acceptors.. The experimental data is fitted using the single-carrier SCLC model (solid lines; cf. details in the SI).

Table 3. SCLC carrier mobility estimates for optimized BHJ thin films with P2TPDBT[2F]T and P2TPD[2F]T, and the polymer donor PBDT-TS1.

$\begin{array}{cccc} & \mu_{\mathrm{h}} & \mu_{\mathrm{e}} & \\ \text { Polymer Acceptor } & {\left[\mathrm{cm}^{2} \mathrm{~V}^{-1} \mathrm{~s}^{-1}\right]} & \begin{array}{c}\left.\mathrm{cm}^{2} \mathrm{~V}^{-1} \mathrm{~s}^{-1}\right] \\ \mu_{\mathrm{h}} / \mu_{\mathrm{e}}\end{array} \\ \text { P2TPD[2F]T } & 3.0 \times 10^{-4} & 2.4 \times 10^{-7} & 1250 \\ \text { P2TPDBT[2F]T } & 3.1 \times 10^{-4} & 6.1 \times 10^{-5} & 5.1\end{array}$

P2TPD $[2 F] T$ counterparts. In parallel, the more favorable balance between hole and electron mobilities in P2TPDBT[2F]T-based BHJ solar cells is worthwhile noting: with $\mu_{\mathrm{h}} / \mu_{\mathrm{e}}$ reaching 5.1 vs. 1250 in $\mathrm{P} 2 \mathrm{TPD}[2 \mathrm{~F}] \mathrm{T}$-based $\mathrm{BHJ}$ devices. Balanced carrier mobilities benefit FF, $J_{\mathrm{SC}}$, and overall PCE values in BHJ solar cells. ${ }^{[6]}$

Inadequate BHJ thin-film networks and carrier mobility imbalances can induce significant charge recombination effects across the active layer. ${ }^{[6,25,69-71]}$ To probe those effects in optimized blend films of the TPD/[2F]T-based polymer acceptors and PBDT-TS1 as the polymer donor, we studied the $J_{\mathrm{SC}}$ and $V_{\mathrm{OC}}$ as a function of light intensity; the results are shown in Figure 9. A power-law dependence of $J_{\mathrm{SC}}$ on light intensity (P) was observed and can be expressed as $J_{\mathrm{SC}}$ $\propto \mathrm{P}^{\alpha},{ }^{[72-73]}$ with $\alpha$ being close to unity: result indicative of a weak bimolecular recombination regime. ${ }^{[72-73]}$ As shown in Figure 9a, optimized PBDT-TS1:P2TPDBT[2F]T active layers showed a higher slope $(\alpha=0.964)$ compared with that obtained for PBDT-TS1:P2TPD[2F]T devices $(\alpha=$ 


\section{WILEY-VCH}

0.917), pointing to lesser bimolecular recombination events at short circuit in P2TPDBT[2F]Tbased devices. Figure $9 \mathrm{~b}$ provides the dependence of $V_{\mathrm{OC}}$ on $\mathrm{P}$ in the all-polymer BHJ devices. The slope of $V_{\mathrm{OC}} v s$. ln $\mathrm{P}$ can be used to determine the degree of trap-assisted recombination across the active layers. A slope of 2kT/q or $>\mathrm{kT} / \mathrm{q}$ (where $\mathrm{k}$ denotes the Boltzmann's constant; $\mathrm{T}$, temperature; and $\mathrm{q}$, the elementary charge) implies that trap-assisted recombination is
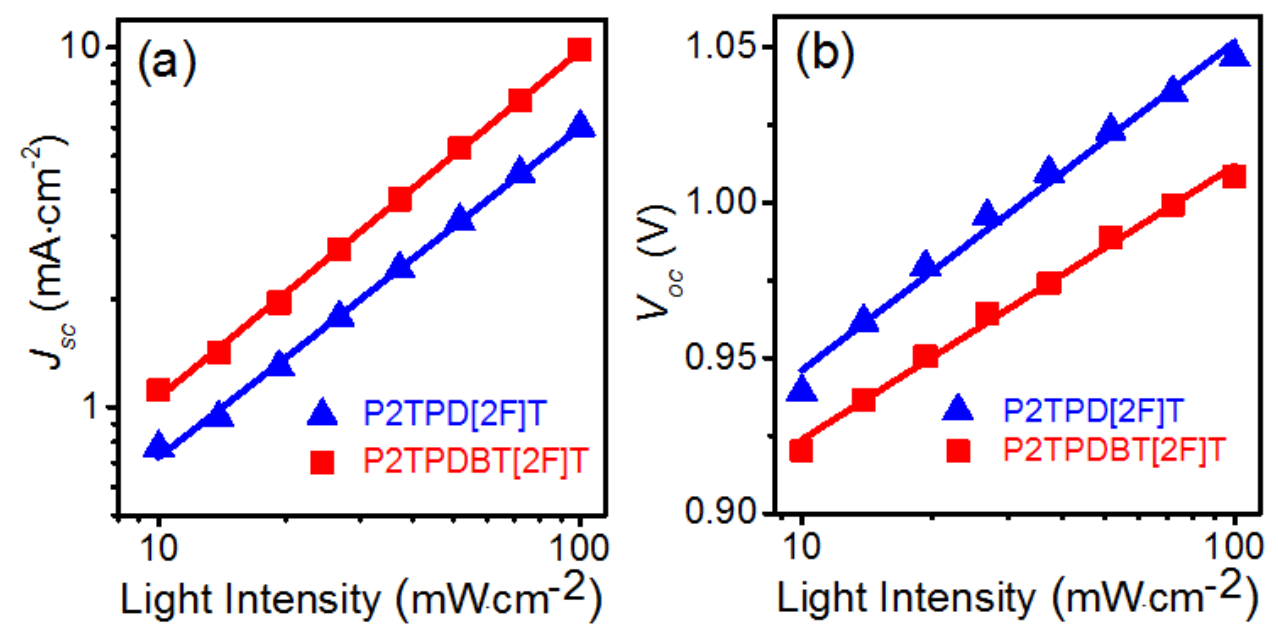

Figure 9. Measured (a) $J_{\mathrm{SC}}$ and (b) $V_{\mathrm{OC}}$ of optimized BHJ solar cells with P2TPDBT[2F]T and P2TPD[2F]T, and the Polymer Donor PBDT-TS1, plotted vs. light intensity (symbols) on a logarithmic scale, together with the linear fits to the data (solid lines).

a significant loss channel at open circuit. ${ }^{[74-75]}$ Our analyses show that PBDT-TS1:P2TPD[2F]T devices yield a slope of $1.62 \mathrm{kT} / \mathrm{q}$, whereas PBDT-TS1:P2TPDBT[2F]T devices yield a smaller slope of $1.39 \mathrm{kT} / \mathrm{q}$. These results reflect a lesser extent of interfacial traps in P2TPDBT[2F]Tbased BHJ solar cells. ${ }^{[74-75]}$ The limited charge recombination effects and the more balanced electron and hole mobilities in P2TPDBT[2F]T-based BHJ devices, together with the more 


\section{WILEY-VCH}

extended optical absorption footprint of P2TPDBT[2F]T, can be concluded to represent the main contributing factors to the higher $J_{S C}$ and PCE values reached with the polymer acceptor P2TPDBT[2F]T.

\section{Conclusion}

In summary, we have shown that alternating $\pi$-conjugated polymers composed of thieno[3,4c]pyrrole-4,6-dione (TPD) and 3,4-difluorothiophene ([2F]T) motifs can be used as fullerene alternatives in "all-polymer" BHJ solar cells. While BHJ devices fabricated with $\mathrm{P} 2 \mathrm{TPD}[2 \mathrm{~F}] \mathrm{T}$ and the polymer donor PBDT-TS1 (taken as model system) can only reach PCEs of $c a .2 .6 \%$ (max.), our systematic device optimizations indicate that all-polymer BHJ solar cells made with P2TPDBT[2F]T and PBDT-TS1 can achieve PCEs of up to $c a .4 .8 \%$; combining a large opencircuit voltage $\left(V_{\mathrm{OC}}\right)$ of $c a .1 .0 \mathrm{~V}$ and high short-circuit current values $\left(J_{\mathrm{SC}}\right)$ of $c a .11 .0 \mathrm{~mA} \mathrm{~cm}^{-2}$. In P2TPDBT[2F]T, the introduction of the electron-deficient motif 2,1,3-benzothiadiazole (BT) narrows the optical gap $\left(E_{\mathrm{opt}}\right)$ to $1.7 \mathrm{eV}$ (from $c a .1 .9 \mathrm{eV}$ in P2TPD[2F]T) and enhances the solar cell $\mathrm{EQE}$ in the 550-650 nm wavelength range. Concurrently, our device analyses point to a rise in electron mobility from $2.4 \times 10^{-7} \mathrm{~cm}^{2}(\mathrm{~V} . \mathrm{s})^{-1}$ in BHJ thin films with $\mathrm{P} 2 \mathrm{TPD}[2 \mathrm{~F}] \mathrm{T}$, up to $6.1 \times 10^{-5} \mathrm{~cm}^{2}(\mathrm{~V} . \mathrm{s})^{-1}$ with P2TPDBT[2F]T. The higher electron mobilities and reduced carrier imbalance and recombination effects in P2TPDBT[2F]T-based BHJs all contribute to the significant device $J_{\mathrm{SC}}, \mathrm{EQE} / \mathrm{IQE}$ and PCE variations observed in the optimized solar cells. While both $\mathrm{TPD} /[2 \mathrm{~F}] \mathrm{T}-$ based polymer acceptors can be used as fullerene alternatives in BHJ solar cells, 


\section{WILEY-VCH}

the narrow-gap P2TPDBT[2F]T analogue shows significant promise as a nonfullerene acceptor for efficient all-polymer BHJ solar cells. Our study demonstrates that adequately-substituted "all-thiophene"-based polymer acceptors and derivatized analogues can broaden the class of systems for further examinations of the "all-polymer" BHJ concept. The consideration of other polymer donors will also be of importance in future work with P2TPDBT[2F]T polymers.

\section{Experimental Section}

Material Characterizations: All compounds were characterized by NMR spectroscopy on Bruker Avance III Ultrashield Plus instruments using a $400 \mathrm{MHz}$ proton frequency. Highresolution mass spectrometry (HRMS) data was recorded using a Thermo Scientific - LTQ Velos Orbitrap MS. Information on materials, synthetic methods and protocols for the syntheses of SM1-4 are detailed in the Supporting Information (SI). Further details on PESA, UV-vis, TGA, DSC, and solid-state NMR instrumentation and experimental conditions are developed in the SI.

Computational Analyses: All density functional theory (DFT) calculations were performed at the tuned $\omega \mathrm{B} 97 \mathrm{X}-\mathrm{D} / 6-31 \mathrm{G}(\mathrm{d}, \mathrm{p})$ level of theory with the Gaussian 09 (Revision D.01) suite of programs. To calculate the torsion potentials, the monomer geometry is first optimized using the $\omega \mathrm{B} 97 \mathrm{X}-\mathrm{D}$ functional with the $\omega$ value for this geometry computed using the IP-tuning procedure. The geometry is then re-optimized using the previously calculated $\omega$ value and this process of IP tuning and re-optimization is continued until the change in the $\omega$ value is less than $10^{-3} \mathrm{Bohr}^{-1}$. 


\section{WILEY-VCH}

This $\omega$ value is used for the geometry optimizations at all dihedral angles. Additional details and references can be found in the SI.

Device Testing Protocols: The solar cells were prepared on glass substrates with tin-doped indium oxide (ITO, $15 \Omega \mathrm{sq}^{-1}$ ) patterned on the surface (device area: $0.1 \mathrm{~cm}^{2}$ ). Information on substrate preparation, active layer and contact depositions are detailed in the SI. Solar cell $J-V$ measurements were performed in the glovebox with a Keithley 2400 source meter and an Oriel Sol3A Class AAA solar simulator calibrated to 1 sun, AM1.5 G, with a KG-5 silicon reference cell certified by Newport. The external quantum efficiency (EQE) measurements were performed at zero bias by illuminating the device with monochromatic light supplied from a Xenon arc lamp in combination with a dual-grating monochromator. The number of photons incident on the sample was calculated for each wavelength by using a silicon photodiode calibrated by NIST. Additional details on various active layer deposition conditions, TEM instrumentation, and carrier mobility measurements are developed in the SI.

\section{Supporting Information}

Experimental methods, characterization, and additional figures and tables. Supporting Information is available from the Wiley Online Library or from the authors.

\section{Acknowledgements}

The authors acknowledge financial support under Baseline Research Funding from King Abdullah University of Science and Technology (KAUST) and from ONR-Global (Award 


\section{WILEY-VCH}

N62909-15-1-2003 to JLB). The authors thank KAUST ACL for mass spectrometry, GPC and elemental analyses, and are grateful to the KAUST Supercomputing Laboratory (KSL) and IT Research Computing Teams for providing continuous assistance as well as computational and storage resources. The authors thank R.-Z. Liang and M. Babics for their contributions in device characterizations. S. Liu and X. Song contributed equally to this work.

Received: ((will be filled in by the editorial staff))

Revised: ((will be filled in by the editorial staff)) Published online: ((will be filled in by the editorial staff))

\section{References:}

[1] J. J. M. Halls, C. A. Walsh, N. C. Greenham, E. A. Marseglia, R. H. Friend, S. C. Moratti, A. B. Holmes, Nature 1995, 376, 498.

[2] G. Yu, A. J. Heeger, J. Appl. Phys. 1995, 78, 4510.

[3] J. Zhao, Y. Li, G. Yang, K. Jiang, H. Lin, H. Ade, W. Ma, H. Yan, Nat. Energy 2016, 1, 15027.

[4] Z. Wu, C. Sun, S. Dong, X. Jiang, S. Wu, H. Wu, H. Yip, F. Huang, Y. Cao, J. Am. Chem. Soc. 2016, 138, 2004.

[5] P. M. Beaujuge, J. M. J. Fréchet, J. Am. Chem. Soc. 2011, 133, 20009.

[6] A. Facchetti, Mater. Today 2013, 16, 123.

[7] Y. Lin, X. Zhan, Mater. Horiz. 2014, 1, 470.

[8] H . Benten, D. Mori, H. Ohkita, S. Ito, J. Mater. Chem. A 2016, 4, 5340.

[9] T. Kim, J.-H. Kim, T. E. Kang, C. Lee, H. Kang, M. Shin, C. Wang, B. Ma, U. Jeong, T.-S. Kim, B. J. Kim, Nat. Commun. 2015, 6, 8547.

[10] H. Kang, W. Lee, J. Oh, T. Kim, C. Lee, B. J. Kim, Acc. Chem. Res. 2016, DOI: 10.1021/acs.accounts.6b00347. 


\section{WILEY-VCH}

[11] C. B. Nielsen, S. Holliday, H.-Y. Chen, S. J. Cryer, I. McCulloch, Acc. Chem. Res. 2015, 48, 2803.

[12] B. C. Thompson, J. M. J. Fréchet, Angew. Chem., Int. Ed. 2008, 47, 58.

[13] G. Yu, J. Gao, J. C. Hummelen, F. Wudl, A. J. Heeger, Science 1995, 270, 1789.

[14] C. J. Brabec, S. Gowrisanker, J. J. Halls, D. Laird, S. Jia, S. P. Williams, Adv. Mater. 2010 , 22,3839 .

[15] J. C. Hummelen, B. W. Knight, F. LePeq, F. Wudl, J. Yao, C. L. Wilkins, J. Org. Chem. $1995,60,532$.

[16] M. M. Wienk, J. M. Kroon, W. J. H. Verhees, J. Knol, J. C. Hummelen, P. A. van Hal, R. A. J. Janssen, Angew. Chem., Int. Ed. 2003, 42, 3371.

[17] Y. He, H.-Y. Chen, J. Hou, Y. Li, J. Am. Chem. Soc. 2010, 132, 1377.

[18] E. Zhou, J. Cong, Q. Wei, K. Tajima, C. Yang, K. Hashimoto, Angew. Chem., Int. Ed. 2011, $50,2799$.

[19] P. Cheng, L. Ye, X. Zhao, J. Hou, Y. Li, X. Zhan, Energy Environ. Sci. 2014, 7, 1351.

[20] Y. Zhou, T. Kurosawa, W. Ma, Y. Guo, L. Fang, K. Vandewal, Y. Diao, C. Wang, Q. Yan, J. Reinspach, J. Mei, A. L. Appleton, G. I. Koleilat, Y. Gao, S. C. B. Mannsfeld, A. Salleo, H. Ade, D. Zhao, Z. Bao, Adv. Mater. 2014, 26, 3767.

[21] S. Li, H. Zhang, W. Zhao, L. Ye, H. Yao, B. Yang, S. Zhang, J. Hou, Adv. Energy Mater. 2016, 6, 1501991.

[22] I. H. Jung, D. Zhao, J. Jang, W. Chen, E. S. Landry, L. Lu, D. V. Talapin, L. Yu, Chem. Mater. 2015, 27, 5941.

[23] Y.-J. Hwang, B. A. E. Courtright, A. S. Ferreira, S. H. Tolbert, S. A. Jenekhe, Adv. Mater. 2015, 27, 4578 .

[24] J. W. Jung, J. W. Jo, C.-C. Chueh, F. Liu, W. H. Jo, T. P. Russell, A. K. Y. Jen, Adv. Mater. 2015, 27, 3310 . 


\section{WILEY-VCH}

[25] C. Lee, H. Kang, W. Lee, T. Kim, K.-H. Kim, H. Y. Woo, C. Wang, B. J. Kim, Adv. Mater. 2015, 27, 2466.

[26] X. Zhan, Z. Tan, B. Domercq, Z. An, X. Zhang, S. Barlow, Y. Li, D. Zhu, B. Kippelen, S. R. Marder, J. Am. Chem. Soc. 2007, 129, 7246.

[27] C. Mu, P. Liu, W. Ma, K. Jiang, J. Zhao, K. Zhang, Z. Chen, Z. Wei, Y. Yi, J. Wang, S.

Yang, F. Huang, A. Facchetti, H. Ade, H. Yan, Adv. Mater. 2014, 26, 7224.

[28] L. Gao, Z.-G. Zhang, L. Xue, J. Min, J. Zhang, Z. Wei, Y. Li, Adv. Mater. 2016, 28, 1884.

[29] Z. Li, X. Xu, W. Zhang, X. Meng, W. Ma, A. Yartsev, O. Inganäs, M. R. Andersson, R. A. J. Janssen, E. Wang, J. Am. Chem. Soc. 2016, 138, 10935.

[30] X. Long, Z. Ding, C. Dou, J. Zhang, J. Liu, L. Wang, Adv. Mater. 2016, 28, 6504.

[31] W. Li, W. S. C. Roelofs, M. Turbiez, M. M. Wienk, R. A. J. Janssen, Adv. Mater. 2014, 26, 3304.

[32] D. Mori, H. Benten, H. Ohkita, S. Ito, K. Miyake, ACS Appl. Mater. Interfaces 2012, 4, 3325 .

[33] C. R. McNeill, A. Abrusci, J. Zaumseil, R. Wilson, M. J. McKiernan, J. H. Burroughes, J. J. M. Halls, N. C. Greenham, R. H. Friend, Appl. Phys. Lett. 2007, 90, 193506.

[34] R. Stalder, J. Mei, J. Subbiah, C. Grand, L. A. Estrada, F. So, J. R. Reynolds, Macromolecules 2011, 44, 6303.

[35] T. W. Holcombe, C. H. Woo, Kavulak, B. C. Thompson, J. M. J. Fréchet, J. Am. Chem. Soc. 2009, 131,14160 .

[36] C. Cabanetos, A. El Labban, J. A. Bartelt, J. D. Douglas, W. R. Mateker, J. M. J. Frechet, M. D. McGehee, P. M. Beaujuge, J. Am. Chem. Soc. 2013, 135, 4656.

[37] C. Piliego, T. W. Holcombe, J. D. Douglas, C. H. Woo, P. M. Beaujuge, J. M. J. Fréchet, J. Am. Chem. Soc. 2010, 132, 7595.

[38] Y. Zou, A. Najari, P. Berrouard, S. Beaupré, B. Réda Aïch, Y. Tao, M. A. Leclerc, J. Am. Chem. Soc. 2010, 132, 5330. 


\section{WILEY-VCH}

[39] J. Warnan, C. Cabanetos, A. E. Labban, M. R. Hansen, C. Tassone, M. F. Toney, P. M. Beaujuge, Adv. Mater. 2014, 26, 4357.

[40] J. Warnan, A. El Labban, C. Cabanetos, E. T. Hoke, P. K. Shukla, C. Risko, J.-L. Brédas, M. D. McGehee, P. M. Beaujuge, Chem. Mater. 2014, 26, 2299.

[41] K. R. Graham, C. Cabanetos, J. P. Jahnke, M. N. Idso, E. Labban, G. O. N. Ndjawa, T.

Heumueller, K. Vandewal, A. Salleo, B. F. Chmelka, A. Amassian, P. M. Beaujuge, M. D. Mcgehee, J. Am. Chem. Soc. 2014, 136, 9608.

[42] Y. Gao, V. M. Le Corre, A. Gaïtis, M. Neophytou, M. A. Hamid, K. Takanabe, P. M. Beaujuge, Adv. Mater. 2016, 28, 3366.

[43] A. Pron, P. Berrouard, M. Leclerc, Macromol. Chem. Phys. 2013, 214, 7.

[44] X. Guo, A. Facchetti, T. J. Marks, Chem. Rev. 2014, 114, 8943.

[45] P. Berrouard, F. Grenier, J. Pouliot, E. Gagnon, C. Tessier, M. Leclerc, Org. Lett. 2011, 13, 38.

[46] F. Grenier, P. Berrouard, J.-R. Pouliot, H.-R. Tseng, A. J. Heeger, M. Leclerc, Polym. Chem. 2013, 4, 1836.

[47] J.-R. Pouliot, L. G. Mercier, S. Caron, M. Leclerc, Macromol. Chem. Phys. 2013, 214, 453.

[48] J. Wolf, F. Cruciani, A. El Labban, P. M. Beaujuge, Chem. Mater. 2015, 27, 4184.

[49] S. Liu, Z. Kan, S. Thomas, F. Cruciani, J.-L. Brédas, P. M. Beaujuge, Angew. Chem. Int. Ed. 2016, 55, 12996.

[50] J. Chen, Y. Cao, Acc. Chem. Res. 2009, 42, 1709.

[51] O. Inganäs, F. L. Zhang, M. R. Andersson, Acc. Chem. Res. 2009, 42, 1731.

[52] P. L. T. Boudreault, A. Najari, M. Leclerc, Chem. Mater. 2011, 23, 456.

[53] Y. He, Y. Li, Phys. Chem. Chem. Phys., 2011, 13, 1970.

[54] C. J. Mueller, C. R. Singh, M. Fried, S. Huettner, M. Thelakkat, Adv. Funct. Mater. 2015, 25, 2725.

[55] Y. Sakamoto, S. Komatsu, T. Suzuki, J. Am. Chem. Soc. 2001, 123, 4643. 


\section{WILEY-VCH}

[56] M. J. Frisch, et al. Gaussian, Inc.: Wallingford, CT, USA, 2009.

[57] T. Stein, L. Kronik, R. Baer, J. Am. Chem. Soc. 2009, 131, 2818.

[58] J.L. Brédas, Mater. Horiz. 2014,1, 17.

[59] T. Körzdörfer, J.L. Brédas, Acc. Chem. Res. 2014, 47, 3284.

[60] M. Zhang, H. N. Tsao, W. Pisula, C. Yang, A. K. Mishra, K. Müellen, J. Am. Chem. Soc. 2007, 129, 3472.

[61] N. Zhou, A. S. Dudnik, T. I. N. G. Li, E. F. Manley, T. J. Aldrich, P. Guo, H.-C. Liao, Z.

Chen, L. X. Chen, R. P. H. Chang, A. Facchetti, M. Olvera de la Cruz, T. J. Marks, J. Am. Chem. Soc. 2016, 138, 1240.

[62] L. Ye, S. Zhang, W. Zhao, H. Yao, J. Hou, Chem. Mater. 2014, 26, 3603.

[63] J.L. Brédas, J. E. Norton, J. Cornil, V. Coropceanu, Acc. Chem. Res. 2009, 42, 1691.

[64] J. J. M. Halls, J. Cornil, D. A. dos Santos, R. Silbey, D.-H. Hwang, A. B. Holmes, J.L. Bredas, R. H. Friend, Phys. Rev. B 1999, 60, 5721.

[65] D. Veldman, S. C. J. Meskers, R. A. J. Janssen, Adv. Funct. Mater. 2009, 19, 1939.

[66] W. Li, K. H. Hendriks, A. Furlan, M. M. Wienk, R. A. J. Janssen, J. Am. Chem. Soc. 2015, $137,2231$.

[67] K. Kawashima, Y. Tamai, H. Ohkita, I. Osaka, K. Takimiya, Nat Commun 2015, 6,10085.

[68] M. Wang, H. Wang, T. Yokoyama, X. Liu, Y. Huang, Y. Zhang, T.-Q. Nguyen, S. Aramaki, G. C. Bazan, J. Am. Chem. Soc. 2014, 136, 12576.

[69] Y. Huang, E. J. Kramer, A. J. Heeger, G. C. Bazan, Chem. Rev. 2014, 114, 7006.

[70] N. Zhou, H. Lin, S. J. Lou, X. Yu, P. Guo, E. F. Manley, S. Loser, P. Hartnett, H. Huang, M.

R. Wasielewski, L. X. Chen, R. P. H. Chang, A. Facchetti, T. J. Marks, Adv. Energy Mater. 2014, 4, 1300785.

[71] C. R. McNeill, Energy Environ. Sci. 2012, 5, 5653.

[72] I. Riedel, J. Parisi, V. Dyakonov, L. Lutsen, D. Vanderzande, J. C. Hummelen, Adv. Funct. Mater. 2004, 14, 38 . 


\section{WILEY-VCH}

[73] P. Schilinsky, C. Waldauf, C. Brabec, J. Appl. Phys. Lett. 2002, 81, 3885.

[74] M. M. Mandoc, W. Veurman, L. J. A. Koster, B. de Boer, P. W. M. Blom, Adv. Funct. Mater. 2007, 17, 2167.

[75] G. A. H. Wetzelaer, M. Kuik, M. Lenes, P. W. M. Blom, Appl. Phys. Lett. 2011, 99, 153506. 


\section{Thieno[3,4-c]pyrrole-4,6-dione-based Polymer Acceptors for}

\section{High Open-Circuit Voltage All-Polymer Solar Cells}

Shengjian Liu, ${ }^{\dagger, \&}$ Xin Song, ${ }^{\dagger, \&}$ Simil Thomas,,$^{\dagger}$ Zhipeng Kan, ${ }^{\dagger}$ Federico Cruciani, ${ }^{\dagger}$ Frédéric Laquai, ${ }^{\dagger}$ Jean-Luc Bredas, ${ }^{\dagger}$ and Pierre M. Beaujuge ${ }^{*},{ }^{\prime}$

Keywords: all-polymer solar cells, polymer acceptors, thieno[3,4-c]pyrrole-4,6-dione, 3,4difluorothiophene, organic photovoltaics

Table of contents entry:

Alternating $\pi$-conjugated polymers composed of electron-deficient thieno[3,4-c]pyrrole-4,6dione (TPD) and 3,4-difluorothiophene ([2F]T) motifs are proving relevant as fullerene alternatives for "all-polymer" BHJ solar cells. When a third electron-deficient motif - namely 2,1,3-benzothiadiazole (BT) - is inserted in the main chain, the corresponding polymer (P2TPDBT[2F]T) yields a twofold increase in BHJ device efficiency.
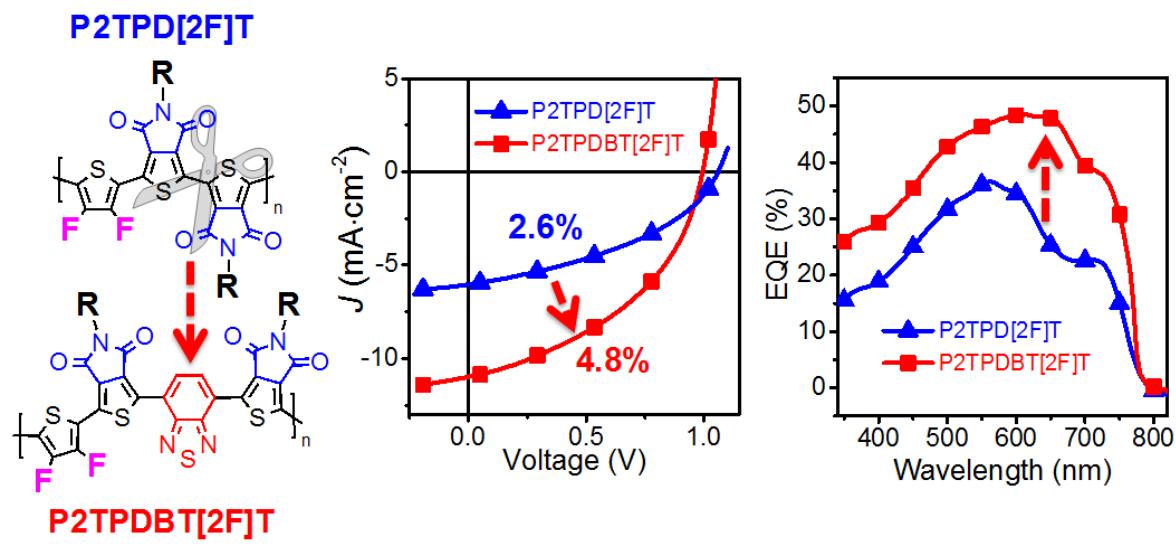